\title{
REVIEW
}

\section{The Interdecadal Shift of ENSO Properties in 1999/2000: A Review}

\author{
Zeng-ZHen Hu AND ARUn KumAR \\ Climate Prediction Center, NCEP/NWS/NOAA, College Park, Maryland \\ BOHUA HUANG \\ Department of Atmospheric, Oceanic, and Earth Sciences and Center for Ocean-Land-Atmosphere Studies, George Mason \\ University, Fairfax, Virginia \\ JiESHUN ZHU AND MiChELle L'HEUREUX \\ Climate Prediction Center, NCEP/NWS/NOAA, College Park, Maryland \\ MiCHAEL J. MCPHADEN \\ NOAA/Pacific Marine Environment Laboratory, Seattle, Washington \\ JIN-YI YU \\ Department of Earth System Science, University of California, Irvine, Irvine, California
}

(Manuscript received 30 April 2019, in final form 12 November 2019)

\begin{abstract}
Following the interdecadal shift of El Niño-Southern Oscillation (ENSO) properties that occurred in 1976/77, another regime shift happened in 1999/2000 that featured a decrease of variability and an increase in ENSO frequency. Specifically, the frequency spectrum of Niño-3.4 sea surface temperature shifted from dominant variations at quasi-quadrennial ( $\sim 4 \mathrm{yr})$ periods during 1979-99 to weaker fluctuations at quasi-biennial ( $\sim 2 \mathrm{yr})$ periods during 2000-18. Also, the spectrum of warm water volume (WWV) index had almost no peak in 2000-18, implying a nearly white noise process. The regime shift was associated with an enhanced zonal gradient of the mean state, a westward shift in the atmosphere-ocean coupling in the tropical Pacific, and an increase in the static stability of the troposphere. This shift had several important implications. The whitening of the subsurface ocean temperature led to a breakdown of the relationship between WWV and ENSO, reducing the efficacy of WWV as a key predictor for ENSO and thus leading to a decrease in ENSO prediction skill. Another consequence of the higher ENSO frequency after 1999/2000 was that the forecasted peak of sea surface temperature anomaly often lagged that observed by several months, and the lag increased with the lead time. The ENSO regime shift may have altered ENSO influences on extratropical climate. Thus, the regime shift of ENSO in 1999/2000 as well as the model default may account for the higher false alarm and lower skill in predicting ENSO since 1999/2000.
\end{abstract}

\section{Introduction}

The basic physical processes responsible for El NiñoSouthern Oscillation (ENSO) and its global impact on climate, economy, and society have been well documented (Rasmusson and Carpenter 1982; Rasmusson and Wallace 1983; Jin 1997a,b; Latif et al. 1998; Wang and

Corresponding author: Zeng-Zhen Hu, zeng-zhen.hu@noaa.gov
Picaut 2004; McPhaden et al. 2006; National Research Council 2010; Sarachik and Cane 2010; Santoso et al. 2015; Timmermann et al. 2018; Hu et al. 2020). ENSO's worldwide consequences motivated the first successful dynamical ENSO forecast made over 30 years ago (Cane et al. 1986). Since then, progress in understanding the ENSO mechanisms and the improvements in climate models and observational systems, as well as the increases in computation capability, have made routine ENSO forecasts at national and regional centers possible 
(Graham et al. 2011; Barnston et al. 2012; Zheng et al. 2016; Huang et al. 2017b; L'Heureux et al. 2017, 2019).

While tremendous progress has been made in monitoring and understanding ENSO, our prediction capability for ENSO has not shown steady improvement during the past few decades (Kirtman and Pirani 2009). Counterintuitively, ENSO prediction skill decreased after 2000 (Wang et al. 2010; Barnston et al. 2012; Kumar et al. 2015; Zhao et al. 2016). The real-time predictions of the 2010/11 La Niña (Zhang et al. 2013), the 2012/13 El Niño, and the 2014/15 borderline El Niño (McPhaden 2015; Zhu et al. 2016; Levine and McPhaden 2016) are notable examples of failures by a majority of the climate/ ENSO forecast models. Given the improvements in the climate prediction models and the observing system for providing model forecast initial conditions (ICs), it is still a puzzle to explain this decline in predictive skill.

The skill decline after 2000 seems to be associated with changes in the characteristics of ENSO, akin to the interdecadal shift of ENSO characteristics in the mid- to late 1970s when the mean state shifted toward a warmer eastern tropical Pacific and a colder extratropical central North Pacific (e.g., Nitta and Yamada 1989; Wang 1995; Zhang et al. 1997; Trenberth and Stepaniak 2001; McPhaden and Zhang 2009; Capotondi and Sardeshmukh 2017). Afterward, the ENSO period became longer and with larger amplitude (An and Wang 2000). These decadal-interdecadal variations in ENSO characteristics after the late 1970 s led to relatively higher forecast skill of ENSO and higher limit of predictability in the 1980s-1990s (Balmaseda et al. 1995; Kirtman and Schopf 1998). These results are consistent with the theoretical connection of signal-to-noise ratio (SNR) with prediction skill or predictability: large anomalies correspond to large SNR and high predictability (Kumar and Hoerling 2000). In fact, the amplitude of Niño-3.4 sea surface temperature (SST) anomalies (SSTAs) is proportional to the prediction skill not only of Niño-3.4 SSTA but also of global SSTAs (see Fig. 5 of Wang et al. 2010).

Recently, it has been suggested that another ENSO regime shift occurred around 1999/2000 (McPhaden and Zhang 2004; McPhaden 2012; Hu et al. 2013, 2016, $2017 \mathrm{a}, \mathrm{c})$. Key features of the regime shift include a reduction of ENSO variability and an increase of ENSO frequency. In this paper, we provide an up-to-date review of the interdecadal shift in tropical Pacific climate variability by summarizing the changes of ENSO characteristics around 1999/2000, explaining how and why ENSO properties changed across the shift using updated observational data. Also, using observational data, hindcasts, and real-time forecasts from a coupled climate model, we will discuss the consequences and impacts of this ENSO regime shift. The data and methods used in the analysis are briefly described in section 2. Variability and frequency changes in ENSO and the possible connection with mean state changes are reviewed in section 3. The possible impacts of the changes in the character of ENSO on the predictability of ENSO and extratropical climate are examined in section 4 . We conclude with a summary and a discussion of further challenges in section 5 .

\section{Data and methods}

The oceanic variables analyzed in this study include monthly and pentad means of ocean temperature and monthly means of ocean temperature averaged over the top $300 \mathrm{~m}$ (H300) from the Global Ocean Data Assimilation System (GODAS) during 1979-2018 (Behringer 2007), and monthly means of ocean temperature along the equatorial Pacific $\left(2^{\circ} \mathrm{S}-2^{\circ} \mathrm{N}\right)$ from the Tropical Atmosphere Ocean (TAO) mooring array during 1993-2018 (McPhaden et al. 1998). Also used are the monthly SST from the Extended Reconstructed SST version 5 (ERSSTv5; Huang et al. 2017a) with a $2^{\circ} \times 2^{\circ}$ horizontal resolution.

The Niño-3.4 and Niño-3 indices are defined as the averaged SSTA over $5^{\circ} \mathrm{S}-5^{\circ} \mathrm{N}, 170^{\circ}-120^{\circ} \mathrm{W}$ and $5^{\circ} \mathrm{S}-5^{\circ} \mathrm{N}$, $150^{\circ}-90^{\circ} \mathrm{W}$, respectively. Following Meinen and McPhaden (2000), the warm water volume (WWV) index is calculated as the average of the depth of the $20^{\circ} \mathrm{C}$ isotherm (D20) from GODAS over the region of $5^{\circ} \mathrm{S}-5^{\circ} \mathrm{N}, 120^{\circ} \mathrm{E}-80^{\circ} \mathrm{W}$. Using data from GODAS, the oceanic Kelvin wave index is defined as the standardized projection of the GODAS pentad mean ocean temperature anomalies (OTAs) averaged between the ocean surface and $300 \mathrm{~m}$ onto the first mode of an extended empirical orthogonal function that is computed using OTAs of the upper $300 \mathrm{~m}$ along the equator between $135.5^{\circ} \mathrm{E}$ and $94.5^{\circ} \mathrm{W}$ for each of the 14 contiguous pentad means (Seo and Xue 2005).

The atmospheric variables analyzed include monthly mean wind stress at the surface, monthly zonal wind at $10 \mathrm{~m}$, and 6-hourly zonal wind at $1000 \mathrm{hPa}$ from the NCEP-DOE reanalysis $(\mathrm{R} 2)$ on a $1^{\circ} \times 1^{\circ}$ grid (Kanamitsu et al. 2002), geopotential height at $500 \mathrm{hPa}$ (H500), and the vertical atmosphere temperature profile along the equator between the surface and $200 \mathrm{hPa}$ also from R2. The precipitation data are from the monthly mean Climate Prediction Center Merged Analysis of Precipitation (CMAP; Xie and Arkin 1997), and monthly mean outgoing longwave radiation (OLR) data are from Liebmann and Smith (1996), both on a $2.5^{\circ} \times 2.5^{\circ}$ grid.

To examine the SST prediction skill and its changes in the tropical Pacific, retrospective predictions (or hindcasts) for January 1982-February 2011 and real-time predictions (or forecasts) for March 2011-December 2018 from the NCEP Climate Forecast System version 2 

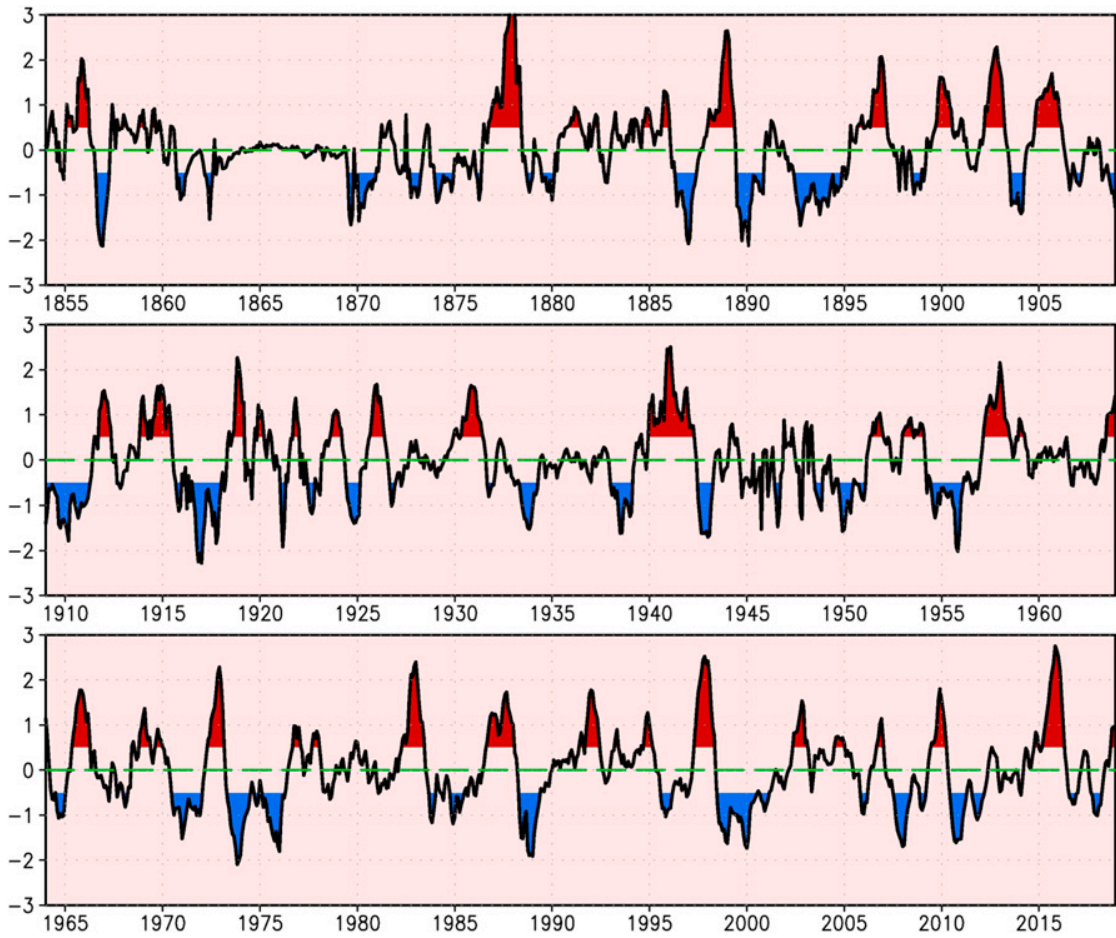

FIG. 1. Monthly mean of the Niño-3.4 index $\left({ }^{\circ} \mathrm{C}\right)$ during January 1854-December 2018. The index is defined as ERSSTv5 SSTA averaged over $5^{\circ} \mathrm{S}-5^{\circ} \mathrm{N}, 120^{\circ}-170^{\circ} \mathrm{W}$. Red shading represents values larger than $0.5^{\circ} \mathrm{C}$ and blue shading for values smaller than $-0.5^{\circ} \mathrm{C}$.

(CFSv2; Saha et al. 2014; Hu et al. 2017d) are analyzed. For hindcasts, four predictions were made every 5 days starting 1 January with ocean and atmosphere ICs from the NCEP Climate Forecast System Reanalysis (CFSR; Saha et al. 2010). There are four forecasts per day from 0000, 0600, 1200, and 1800 UTC and they extend out to 9 months. For this analysis, we used forecasts and hindcasts from 20 ICs in each month to construct ensemble mean predictions.

In addition to composite, regression, and correlation analysis techniques, wavelet analysis (Meyers et al. 1993; $\mathrm{Hu}$ and Nitta 1996) is adopted to reveal the time scale dependence of the variability of the Niño-3.4 and WWV indices, as well as the change in frequency. An advantage of the wavelet analysis over power spectrum analysis is to resolve the time evolution of different frequency components. Also, with different data lengths, such as 1979-99 and $2000-18$, power spectrum analysis cannot give identical spectra for comparison between the two periods. In the calculation, first the wavelet analysis is conducted for the indices over January 1979-December 2018. Then the variances corresponding to different time scales over January 1979-December 1999 and January 2000December 2018 are calculated, respectively.

To examine the atmosphere-ocean coupling strength, the regressions of monthly mean zonal wind stress anomalies onto the Niño-3 index are computed. The area-averaged regression coefficient in the central equatorial Pacific measures the zonal wind-SST feedback (Li et al. 2019b), which is also referred to as the atmospheric Bjerknes feedback index by Lloyd et al. (2009).

\section{Interdecadal change of ENSO}

\section{a. ENSO variability change}

McPhaden (2012), Hu et al. (2013), Lübbecke and McPhaden (2014), and Xu et al. (2019) noted that ENSO amplitude decreased after 2000. Later, it was suggested that the interannual variability of the entire tropical Pacific atmosphere-ocean coupled system decreased after $2000(\mathrm{Hu}$ et al. 2016, 2017a). The reduction in variability remains consistent even when the analysis period is extended to December 2018 to include the extreme El Niño event in 2015/16 and two La Niña events in 2016/17 and 2017/18 (Fig. 1). In fact, the variability decrease is most noticeable in the eastern tropical Pacific instead of the Niño-3.4 region. For instance, compared with 1979-99, the SST variance decreased significantly in the eastern tropical Pacific and increased slightly in the central tropical Pacific during 2000-18 (Fig. 2a). This is consistent with the more frequent occurrence of so-called central Pacific ENSO events after 
(a) SST (C**2)

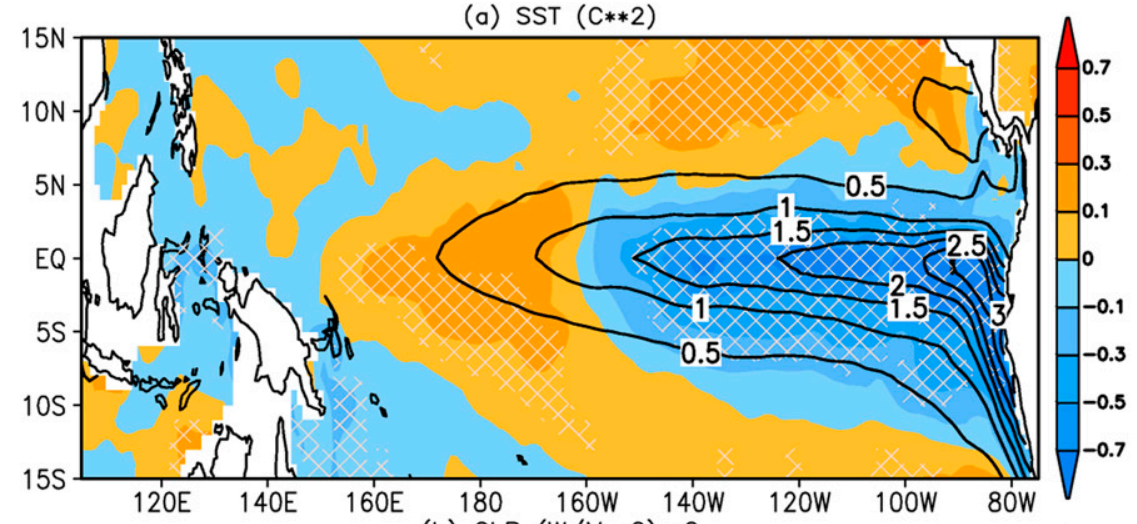

(b) OLR $(\mathrm{W} / \mathrm{M} * 2) * * 2$
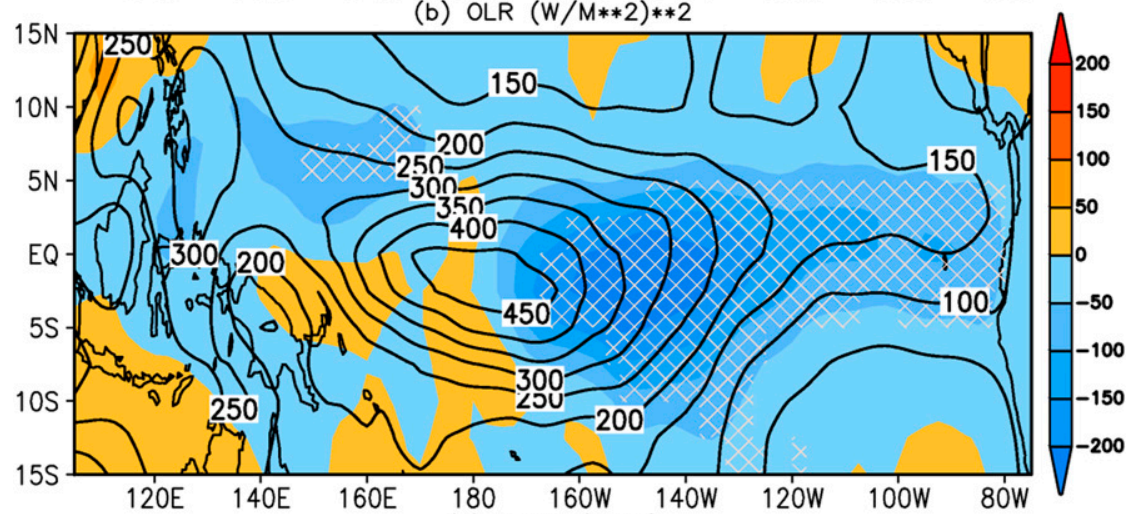

(c) $\mathrm{H} 300(\mathrm{C} * * 2)$

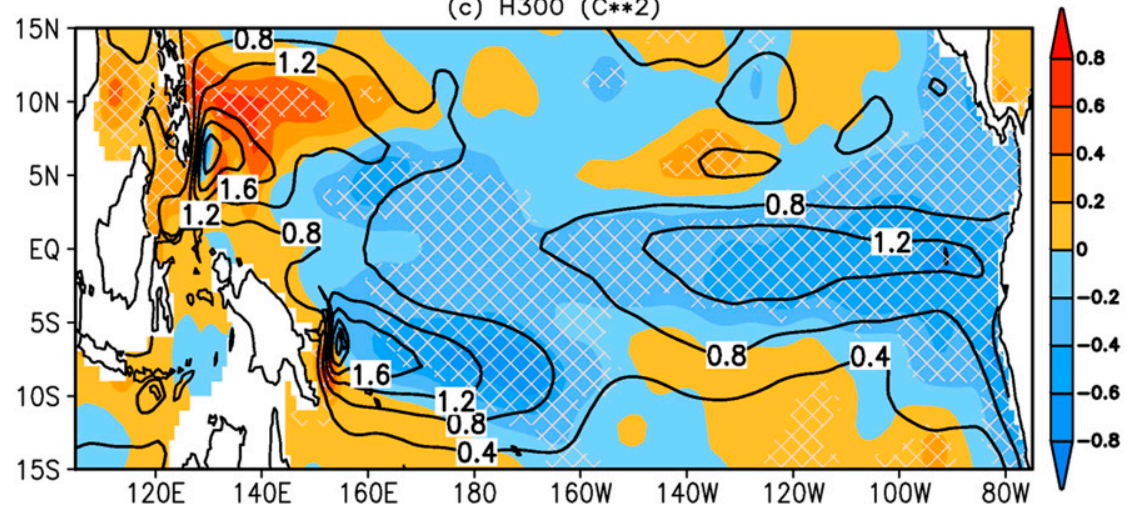

FIG. 2. Shadings are the variance differences of (a) SST $\left({ }^{\circ} \mathrm{C}^{2}\right)$, (b) OLR $\left[\left(\mathrm{W} \mathrm{m}^{-2}\right)^{2}\right]$, and (c) H300 $\left({ }^{\circ} \mathrm{C}^{2}\right)$ between January 2000-December 2018 and January 1979-December 1999. Contours are the variances for January 1979-December 1999. Hatched regions are significant for the difference of the variance by testing the ratio of the variance between the two periods at the $95 \%$ significance level of an $F$ test.

2000 (Kao and Yu 2009; Yeh et al. 2009; Hu et al. 2012a). Consistent with the significant change of SST variability, the variability in atmospheric deep convection (represented by OLR) also significantly decreased in the eastern tropical Pacific after 2000 (Fig. 2b).

In addition to the change in atmospheric variability, oceanic thermocline variability in the tropical Pacific also experienced a significant change around 2000. Anomalous H300 variability decreased significantly from 1979-99 to 2000-18 in the tropical Pacific except in the northwestern and southwestern Pacific (Fig. 2c). This is consistent with the differences in variability of OTA between 1979-99 and 2000-18 (contours of Fig. 3b) for GODAS and between 1993-99 and 2000-18 for TAO (contours in Fig. 3e). Interestingly, the maximum and significant reduction of variability of OTA along the equator is immediately above the mean thermocline in the west and below it in the east (Figs. 3b,e), which is consistent with an increasing thermocline slope along the equator (Figs. 3c,f). Also, consistent with the change of the 
GODAS (left) \& TAO (right) Ocean T (C; 2S-2N)

(a) GODAS Mean Difference (99\%)

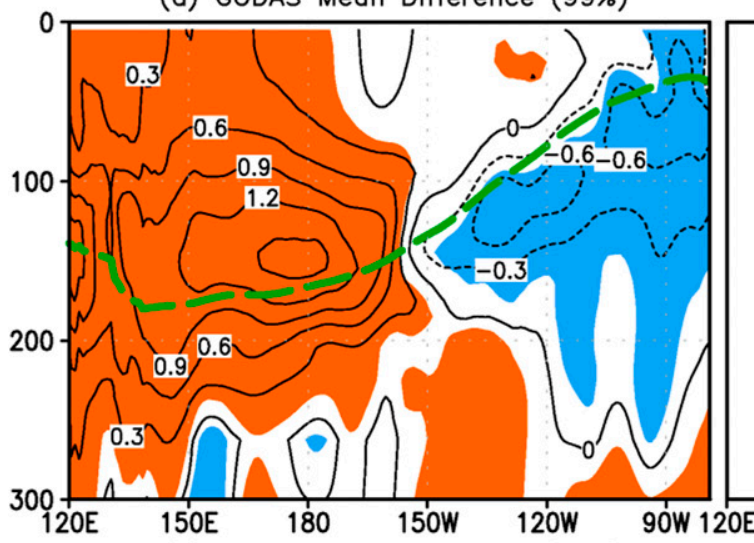

(d) TAO Mean Difference (99\%)

(b) GODAS STDV Difference (99\%)
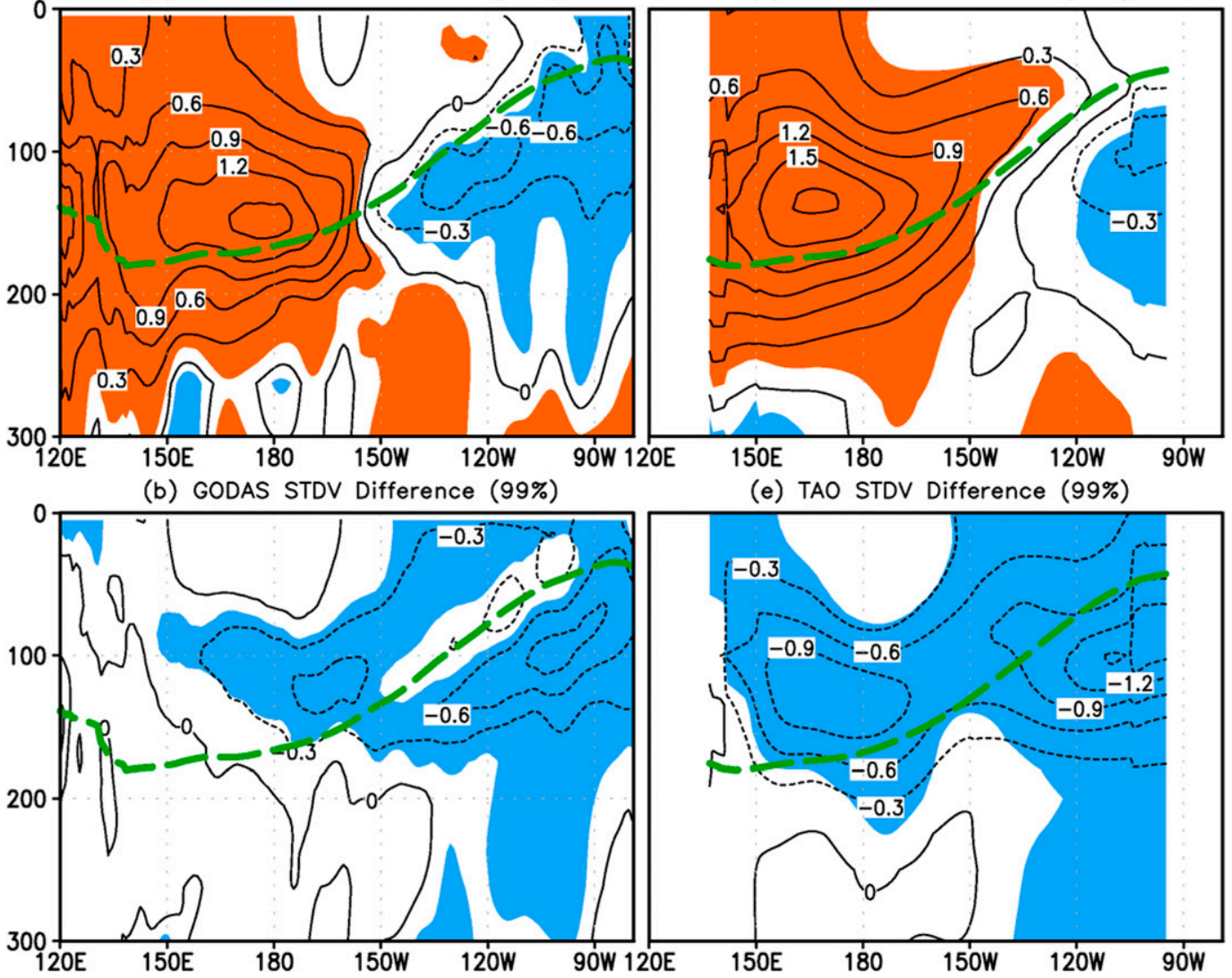

(e) TAO STDV Difference (99\%)

(c) GODAS Mean \& STDV (Shading)

(f) TAO Mean \& STDV (Shading)

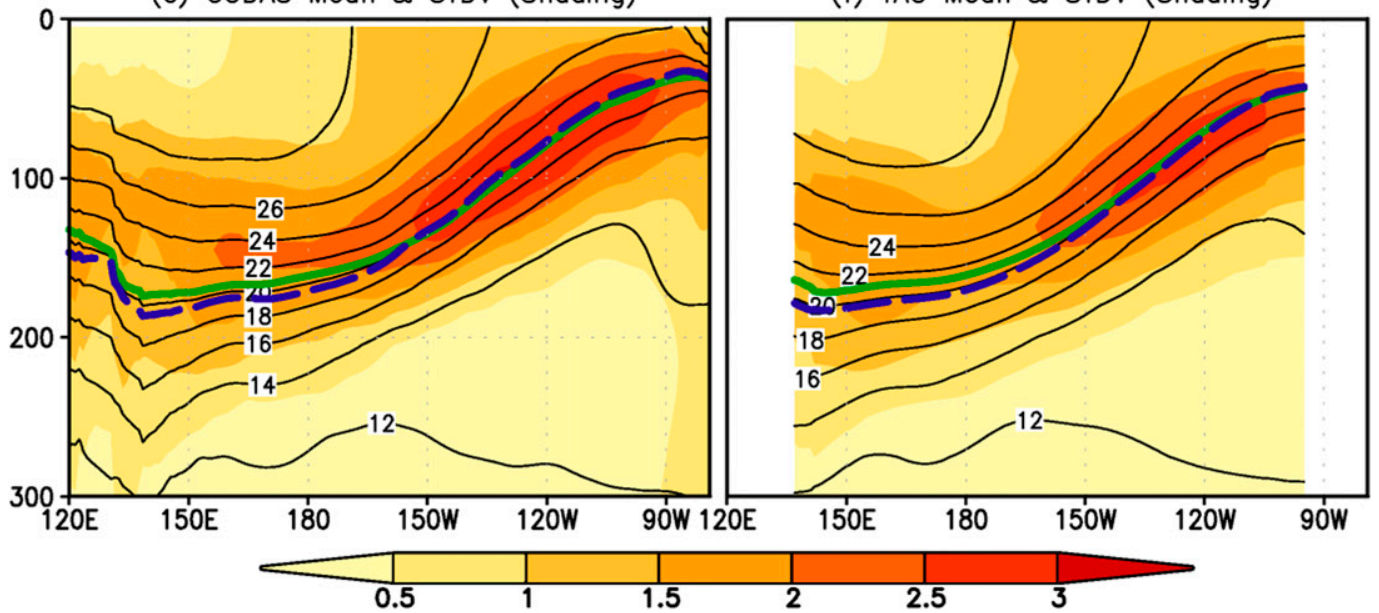

FIG. 3. (a),(d) Differences of the mean (contours) of ocean temperature, (b),(e) differences (contours) of standard deviation of ocean temperature, and (c),(f) mean ocean temperature (contours) and standard deviation (shading); (a)-(c) are calculated based on GODAS data during January 1979-December 2018, and (d)-(f) based on TAO data during January 1993-December 2018. The differences are calculated between means in January 2000-December 2018 and January 1979December 1999 for GODAS, and in January 2000-December 2018 and January 1993-December 1999 for TAO. Contour intervals are $0.3^{\circ} \mathrm{C}$ in (a), (b), (d), and (e) and $2^{\circ} \mathrm{C}$ in (c) and (f). Shading in (a) and (d) represents significant differences of the mean between the two periods at the $99 \%$ significance level of a $t$ test, and in (b) and (e) it represents significant differences of the standard deviation between the two periods at the $99 \%$ significance level of an $F$ test. The green dashed line is the contour of $20^{\circ} \mathrm{C}$ averaged in January 1979-December 2018 for GODAS in (a) and (b) and in January 1993-December 2018 for TAO in (d) and (e). The green solid (dark dashed) lines represent the contour of $20^{\circ} \mathrm{C}$ averaged in January 1979-December 1999 (January 2000-December 2018) for GODAS in (c), and in January 1993-December 1999 (January 2000-December 2018) for TAO in (f), representing the climatological thermocline depth and its interdecadal variation, respectively. All units are ${ }^{\circ} \mathrm{C}$. 

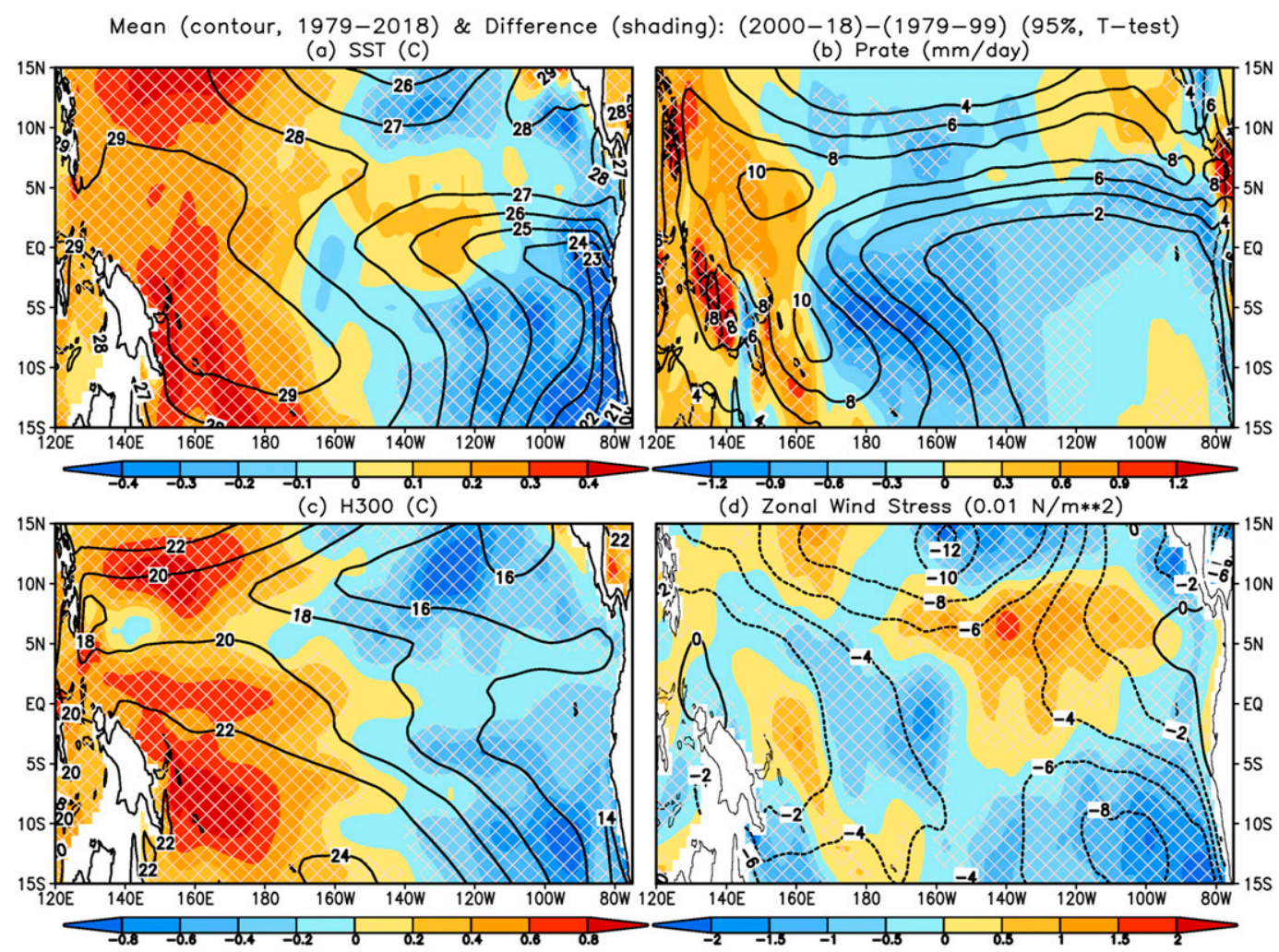

FIG. 4. Differences of (a) SST $\left({ }^{\circ} \mathrm{C}\right)$, (b) precipitation $\left(\mathrm{mm} \mathrm{day}^{-1}\right),(\mathrm{c}) \mathrm{H} 300\left({ }^{\circ} \mathrm{C}\right)$, and (d) surface zonal wind stress $\left(\mathrm{N} \mathrm{m}^{-2}\right)$ between the means in January 2000-December 2018 and in January 1979-December 1999. Hatched regions are significant for the differences at the $95 \%$ significance level of a $t$ test.

thermocline depth (see green solid lines and black dashed lines in Figs. 3c and 3f), the tilt of the thermocline, measured by the D20 difference between the averages in the western and eastern tropical Pacific following Thual et al. (2013), increased significantly (not shown). In fact, the western and eastern parts of WWV may have different features. For example, a recent study of Planton et al. (2018) argued that compared with the eastern part of the WWV, the western part of the WWV has a longer lead time and higher correlation with ENSO than the full WWV, and hence is a better predictor. The reduction of OTA variability was also confirmed by the analysis of the mixed layer ocean heat budget along the equatorial Pacific (not shown). Hu et al. (2016) noted that the amplitudes of both dynamical and thermodynamical terms weakened in the ENSO peak phase after 2000, while there was little change in the developing phase of ENSO. Lübbecke and McPhaden (2014) argued that the change in ENSO variability coincided with the fact that the zonal advection feedback increased while the thermocline feedback declined after 2000. Guan and McPhaden (2016) noted similar decadal shifts from a temperature variance budget analysis in the equatorial Pacific for the period spanning 1980-2010.
These coherent changes in the atmosphere and ocean suggest that the tropical Pacific climate system shifted to a lower variability regime after 2000 compared with that in 1979-99. This regime shift is connected to the change in climatological mean states in the tropical Pacific that has been documented in previous studies (e.g., An and Wang 2000; McPhaden and Zhang 2004; McPhaden et al. 2011; Hu et al. 2013; Xiang et al. 2013). For instance, consistent with the warming in the west and cooling in the east for subsurface ocean temperature along the equatorial Pacific (Figs. 3a,d) and for SSTA (Fig. 4a), the thermocline deepened in the west and shoaled in the east in the tropical Pacific after 2000 (green solid lines and black dashed lines in Figs. 3c and 3f). Meanwhile, the trade winds strengthened in the central tropical Pacific (Fig. 4d) and deep convection and precipitation (Fig. 4b) increased (decreased) in the western (central and eastern) tropical Pacific after 2000, consistent with a strengthened Walker circulation (Hu et al. 2013; L'Heureux et al. 2013a,b).

It is feasible that changes in the mean state and in the variability may be physically connected. By conducting numerical experiments with a simple atmosphere-ocean 
coupled model, Hu et al. (2013) confirmed the linkage between mean states of wind stress and thermocline slope and amplitude of ENSO. They argued that both too strong and too weak mean wind stresses (and too large and too small thermocline slope) along the equatorial Pacific are unfavorable for ENSO growth (see Fig. 6 of Hu et al. 2013; An and Wang 2000). According to Fedorov and Philander (2001), the presence of the delayed oscillator mode requires zonal winds within a certain intensity range, and a thermocline that is neither too shallow nor too deep (see their Fig. 4). A too deep thermocline exerts little impact on SST through its vertical movements and suppresses. Thus, the observed mean conditions after the shift in 1999/2000 (strengthened mean wind stress and thermocline slope) do not favor the growth of ENSO. On the other hand, too weak winds (together with too small thermocline slope) are associated with a reduction of the zonal contrast between the eastern and western Pacific, which is also unfavorable for the formation of ENSO (Fedorov and Philander 2001; Hu et al. 2013).

Furthermore, in addition to the near-surface changes, such as a La Niña-like background pattern and strong divergence in the atmospheric boundary layer over the central tropical Pacific after the late 1990s (Xiang et al. 2013), the mean state change in vertical structure of atmospheric temperature may also have played a role in the interdecadal changes in ENSO. Hu et al. (2017b) proposed that when temperature anomalies in the lower troposphere are larger than in the upper troposphere, the atmosphere is less stable, which favors the development of El Niño. Conversely, weaker positive temperature anomalies in the lower troposphere compared to the upper troposphere inhibit the formation of $\mathrm{El}$ Niño. ENSO evolution in 1997/98 and 2014/15 are examples consistent with this relationship. These two events started from similar and strong positive subsurface ocean temperature anomaly states in the spring of 1997 and 2014, but an extreme El Niño developed in 1997/98 and a borderline El Niño occurred in 2014/15. The different outcomes may be partially due to the differences of the vertical temperature anomaly gradient in the troposphere (and its control on deep convection). Thus, in addition to the significant atmospheric response to ENSO, preconditioning by the vertical gradient of tropospheric temperature may also play a role in ENSO event initiation. However, the evolution of ENSO is determined by multiple factors. For example, Puy et al. (2017) and Zhu et al. (2016) argued that the weak amplitude of El Niño in 2014 may be associated with stochastic variations of westerly wind events (WWEs) or remote influences from outside the equatorial Pacific.
For the differences between 2000-18 and 1979-99 (Fig. 5a), the warming is more pronounced in the upper troposphere than in the lower troposphere. For example, the differences between 300 and $850 \mathrm{hPa}$ (T300T850) are all positive over the equatorial Pacific and reach $0.2^{\circ}-0.6^{\circ} \mathrm{C}$ (Fig. $5 b$ ). This vertical temperature gradient change enhances the atmospheric stability along the equatorial Pacific. This stability is also reflected in the positive change in OLR (suppression of deep convection) along the equator in the Pacific between 2000-18 and 1979-99 located between $175^{\circ} \mathrm{E}$ and $75^{\circ} \mathrm{W}$ (Fig. 5c). Hypothetically, if the positive trend in T300-T850 were caused by the condensational latent heat release, then the convection would have been enhanced (negative OLR differences). Clearly, that is not the case. Thus, this correspondence implies that the more stable atmosphere may be a factor leading to the suppression of deep convection and anomalous trade wind development, which in turn inhibits the Bjerknes feedbacks and growth of ENSO associated anomalies (Clarke 2014). The trend toward increasing atmospheric stratification is consistent with the suppression of convection over the central Pacific and the weakening of atmosphereocean coupling in the tropical Pacific after 2000.

In addition to the change in climatological mean states, other factors may contribute to the reduction of year-to-year variability in the tropical Pacific. For instance, Zhang et al. (2010), McPhaden et al. (2011), and Li et al. (2017) argued that the strengthening of the cold tongue during the past two decades may be associated with ENSO spatial structure diversity and decrease in amplitude. Zhang et al. (2010) proposed a connection of the trends in the tropical Pacific with a so-called cold tongue mode, which is characterized by opposite variations of SST between the Pacific cold tongue and elsewhere in the tropical Pacific. The zonal contrast of the SSTA distribution in their cold tongue mode (see Fig. 1 of Zhang et al. 2010) is similar to the interdecadal variation of SSTA shown in Fig. 4a. However, compared with the broad meridional extent of the interdecadal variation (Fig. 4a), the SSTA associated with their cold tongue mode is confined within $10^{\circ} \mathrm{S}-10^{\circ} \mathrm{N}$ (Zhang et al. 2010). Also, the change in ENSO amplitude might also be associated with changes in various extratropical forcings (Xie et al. 2016; Yu and Fang 2018; Xu et al. 2019).

\section{b. ENSO frequency change}

In addition to the reduction of variability (Figs. 2 and 3), the ENSO frequency also underwent an interdecadal shift after 2000. One may recall that, after around 1976/ 77 , ENSO variability shifted from a high-frequency regime (1962-75) to a low-frequency regime (1980-99) (Wang 1995; Kirtman and Schopf 1998; An and Wang 
(a) Temperature Anomaly Difference Along Equator

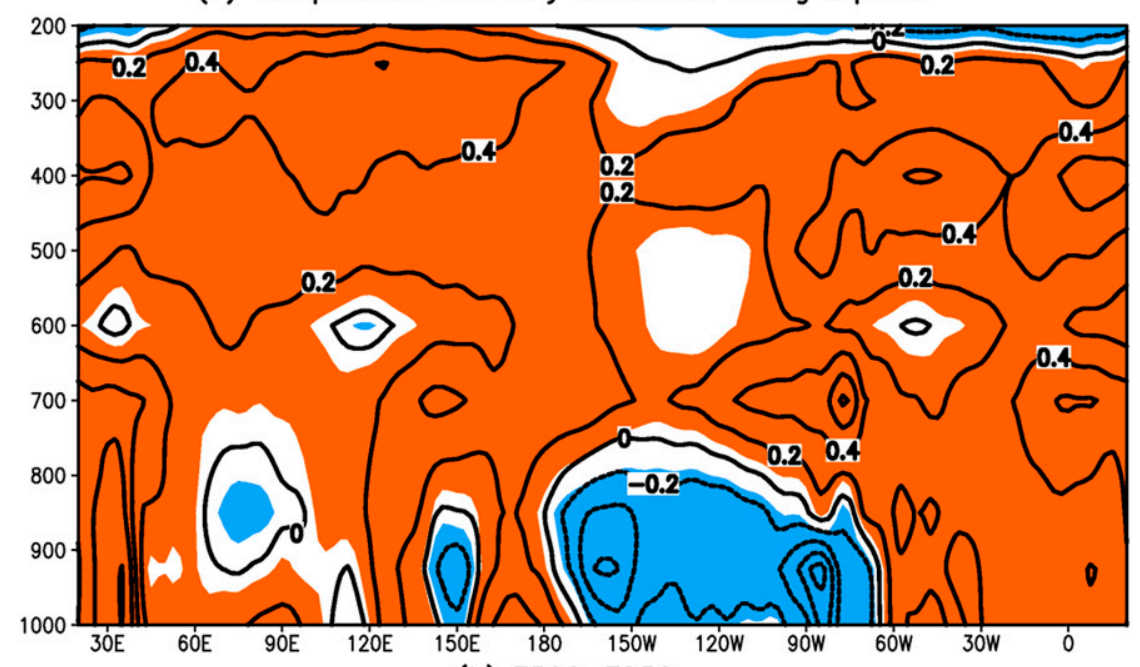

(b) $\mathrm{T} 300-\mathrm{T} 850$
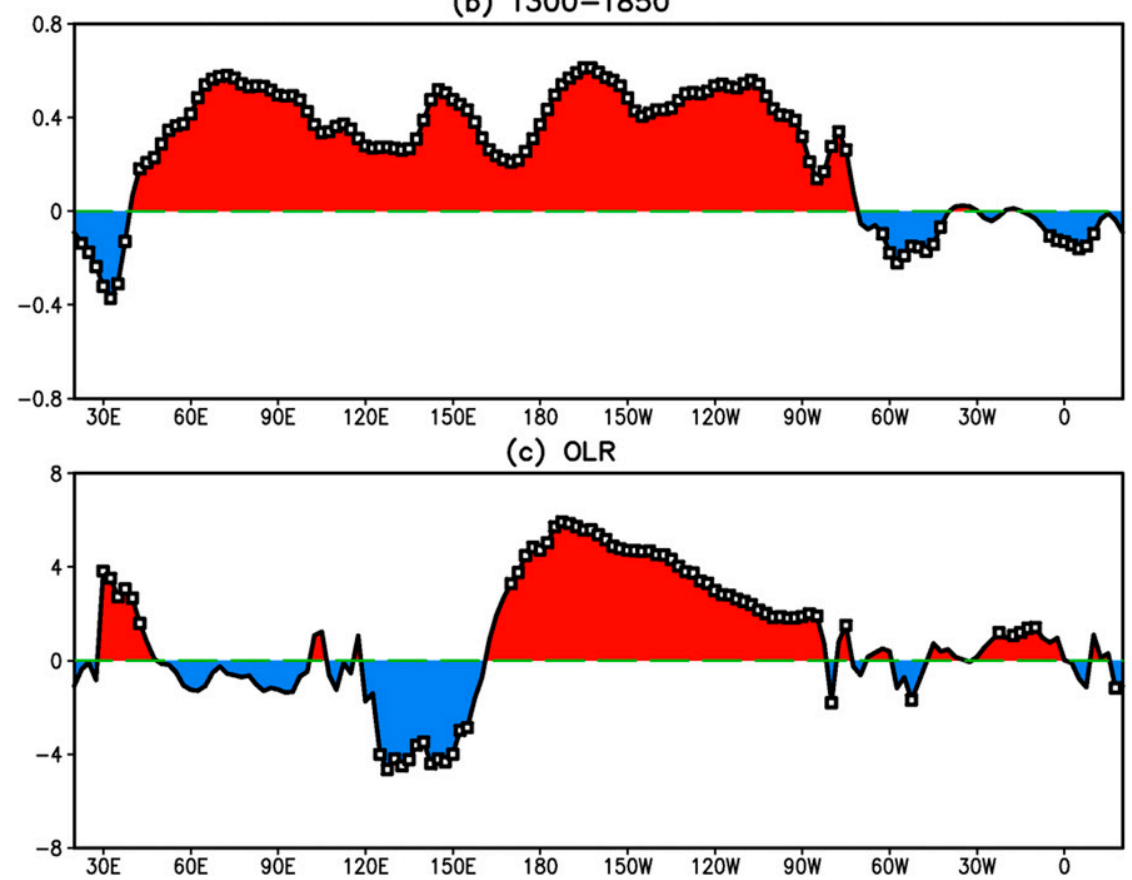

FIG. 5. (a) Air temperature anomaly differences $\left({ }^{\circ} \mathrm{C}\right)$ between January 2000-December 2018 and January $1979-$ December 1999 along the equator averaged in $5^{\circ} \mathrm{S}-5^{\circ} \mathrm{N}$ from the surface to $200 \mathrm{hPa}$; (b) as in (a), but for the differences between 300 and $850 \mathrm{hPa}$. (c) OLR differences $\left(\mathrm{W} \mathrm{m}^{-2}\right.$ ) between January 2000-December 2018 and January 1979-December 1999 along the equator averaged in $5^{\circ} \mathrm{S}-5^{\circ} \mathrm{N}$. The shading in (a) and the curve segments with squares in (b) and (c) represent significant differences between the two periods at the $99 \%$ significance level of a $t$ test.

2000; Wang and An 2002). The high-frequency regime appeared again after 2000. A time-scale decomposition through wavelet analysis (Meyers et al. 1993; Hu and Nitta 1996) of the Niño-3.4 index shows that the maximum variability was confined in the frequency band with periods between 1.5 and 5 years during January 1979-December 1999 (bar in Fig. 6a). The variance distribution became flatter with a much smaller peak around 1.5-3.5 years during January 2000-December 2018 (curve in Fig. 6a). Xie and Jin (2018) argue that there is a connection between ENSO flavors and frequencies. A low-frequency eastern Pacific (EP) ENSOlike mode with the SSTA center in the eastern Pacific with a typical period between 3.5 and 8 years is dominated by thermocline feedback, whereas a central Pacific (CP) ENSO-like mode with the maximum SSTA 

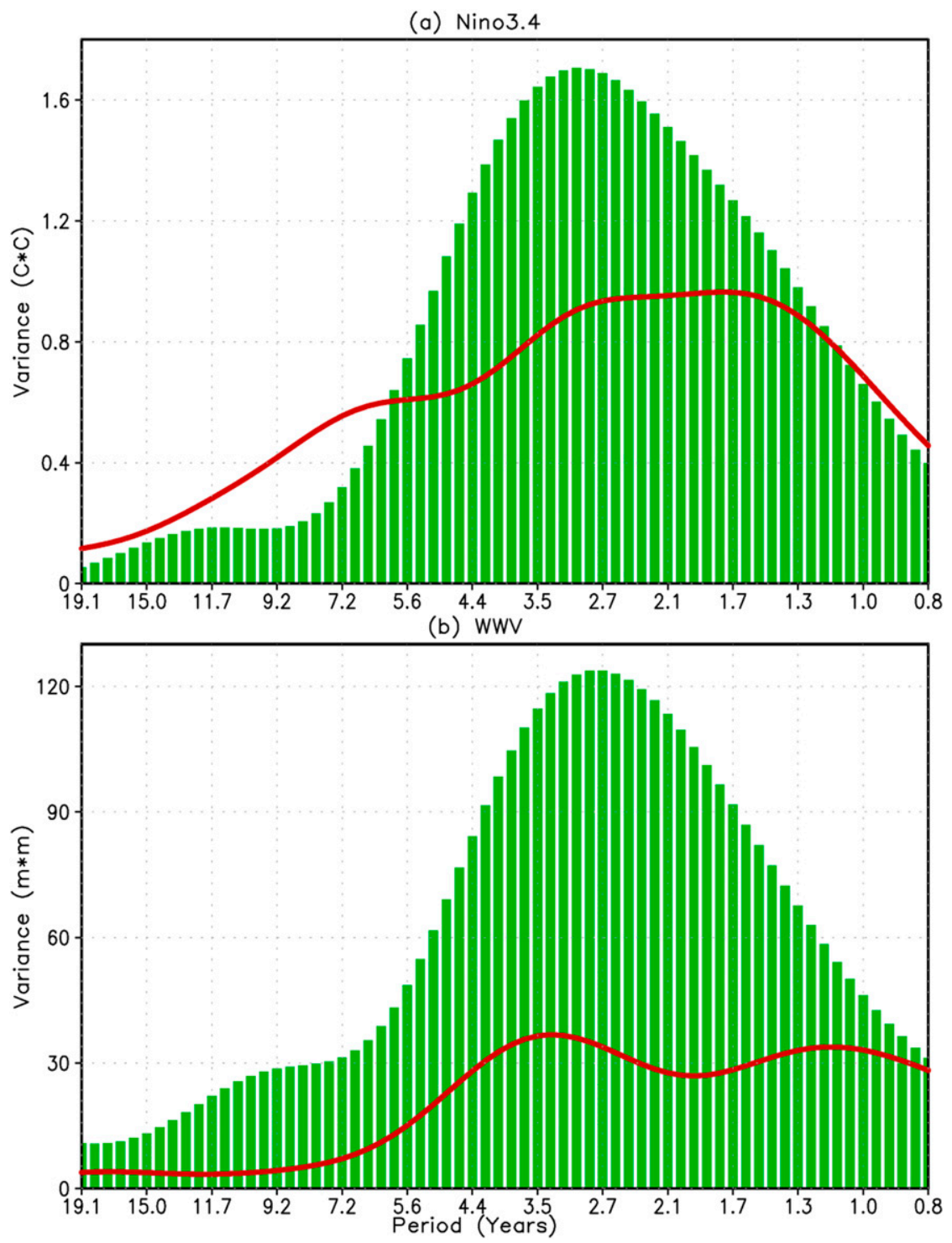

FIG. 6. Variance dependence on time scales of the (a) Niño-3.4 and (b) WWV indices for the average in January 1979-December 1999 (bars) and January 2000-December 2018 (curve), based on the time scale decomposition of wavelet analysis. See text for the details of the calculation. Replotted with updated data after Hu et al. (2017c).

centered more toward the central Pacific oscillates on time scales of $1.5-3$ years and is dominated by zonal advective feedback.

Compared with that of the Niño-3.4 index (Fig. 6a), the frequency shift of the WWV index after 2000 (Fig. 6b) was even more pronounced. During 1979-99, the WWV index had a spectral peak centering in a frequency band of $1.5-5$ years similar to that of the Niño3.4 index, but there was almost no peak for the WWV index during 2000-18 (curve in Fig. 6b). The results are similar if the TAO data (McPhaden et al. 1998) are used to define the WWV index (https://www.pmel.noaa. gov/tao/wwv/data/wwv.dat) (not shown). The result implies that compared with the strong quasi-periodic WWV oscillation during 1979-99, WWV was much closer to a white noise process (equal variance for all frequencies) during 2000-18. Also, compared with 1979-99, the frequency differences between the Niño-3.4 (Fig. 6a) and WWV indices (Fig. 6b) became more appreciable after 2000, implying a decoupling to some extent in the evolution of ENSO SST and upper ocean heat content. This may be one of the main reasons for the decline of ENSO forecast skill after 2000 (Wang et al. 2010; Barnston et al. 2012; Zhang et al. 2013; Kumar et al. 2015; Zhao et al. 2016). 


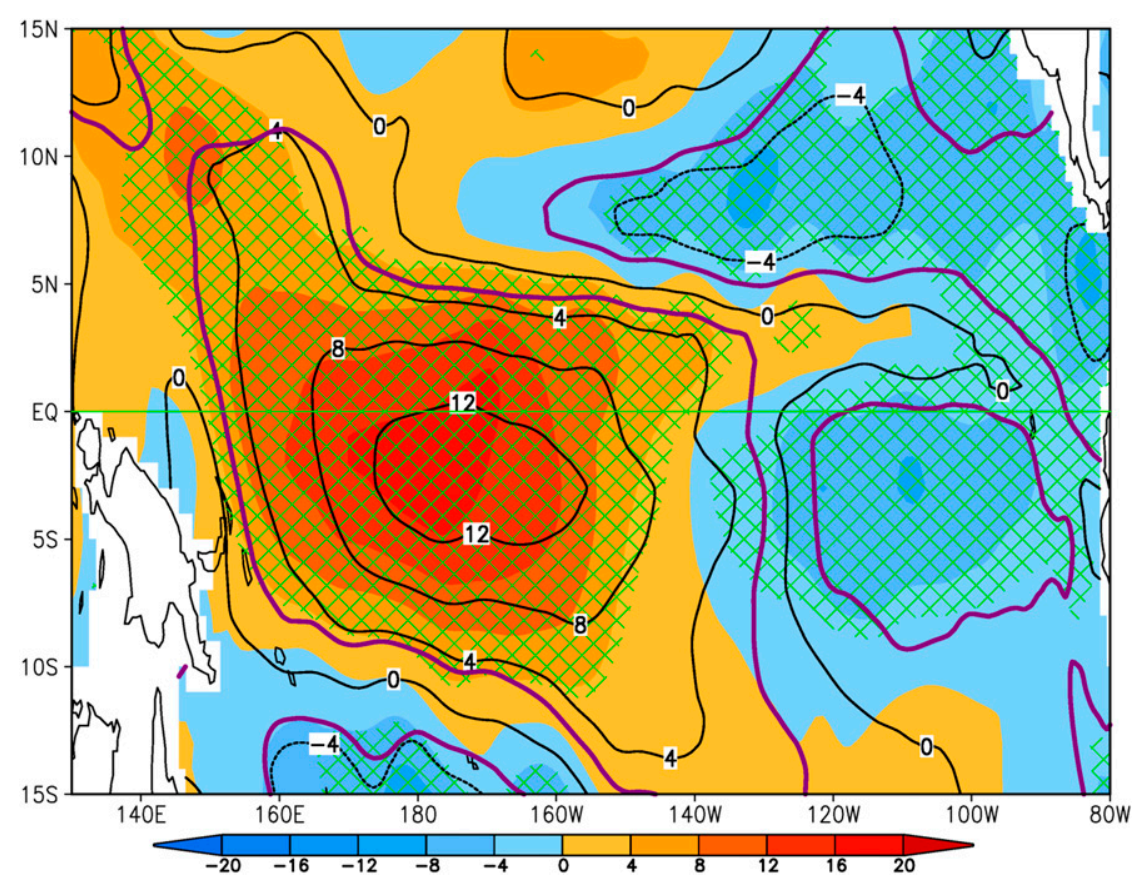

FIG. 7. Simultaneous regressions of surface zonal wind stress anomalies $\left[\mathrm{N}\left(10^{3} \mathrm{~m}^{2}{ }^{\circ} \mathrm{C}\right)^{-1}\right]$ onto the Niño-3 index, which represent the zonal wind-SST feedback in January 1979December 1999 (contours; contour interval is 4) and in January 2000-December 2018 (shading). The hatched regions (purple contours) represent the significance of shading (contour) values at the $99 \%$ significance level of a $t$ test. Replotted with updated data after Hu et al. (2017a) and Li et al. (2019a).

According to An and Wang (2000), the frequency of ENSO is related to the central longitude where atmosphere-ocean coupling occurs. They argue that the impact of the zonal shift of the wind stress on ENSO evolution is mainly through altering advection of the mean SST by anomalous zonal currents. A westward shift of wind stress anomalies reduces the growth of coupled mode and advances the transition of the ENSO cycles, thus resulting in a shorter period with a smaller amplitude. Opposite tendencies occur for an eastward shift in wind stress anomalies. Hu et al. (2017a) and Li et al. (2019a) note the westward shift of climate variability in the tropical Pacific after 2000. Figure 7 shows the mean of zonal wind-SST feedback in 1979-99 (contours) and 2000-18 (shading). Here, the zonal wind-SST feedback is quantified by the regression of monthly mean zonal wind stress anomalies onto the Niño-3 index following Lloyd et al. (2009). Compared to 1979-99, the feedback region shifted northwestward during 2000-18. Consistent with that shift, the westward shift of atmosphere-ocean coupling is also evident in SST, OLR, and the westerly wind energy at $1000 \mathrm{hPa}$ (Fig. 8), as well as both dynamical and thermodynamical terms of the ocean mixed layer heat budget $(\mathrm{Li}$ et al. 2019a). Here, the westerly wind energy is defined as $u_{1000}^{2}$ with $u_{1000}>0.0 \mathrm{~m} \mathrm{~s}^{-1}$, where $u_{1000}$ is the zonal wind at $1000 \mathrm{hPa}$. The statistical significance indicates that the variance decrease is significant for SST from $130^{\circ} \mathrm{W}$ eastward to the coast of South America and in OLR from $162.5^{\circ} \mathrm{W}$ eastward to the coast (Figs. 8a,b).

Such a systematic westward shift is consistent with the following fact: Stronger and more eastward extended westerly wind events in the equatorial Pacific in early months of a year linked with active atmosphere-ocean interaction over the central and eastern tropical Pacific, favoring eastern Pacific El Niño development (Hu et al. 2012a). This also supports the crucial role of westerly wind bursts in generating the diversity of El Niño (Chen et al. 2015). One of possible consequences of the westward shift of the atmosphere-ocean coupling in the tropical Pacific is the increased frequency and shorter lead time in the WWV and Niño-3.4 indices (McPhaden 2012; Kumar and Hu 2014a; Hu et al. 2017c). However, it remains a mystery why there is no noticeable peak in the wavelet analysis of the WWV index after 2000 (line in Fig. 6b), and also what is the impact of ENSO amplitude change and its asymmetry between El Niño and La Niña on the mean state changes (Zhang et al. 2010; McPhaden et al. 2011; Li et al. 2017).

One possible cause of the westward shift of the atmosphere-ocean coupling in the tropical Pacific is the interdecadal change of the mean state (L'Heureux et al. 2013a,b; 

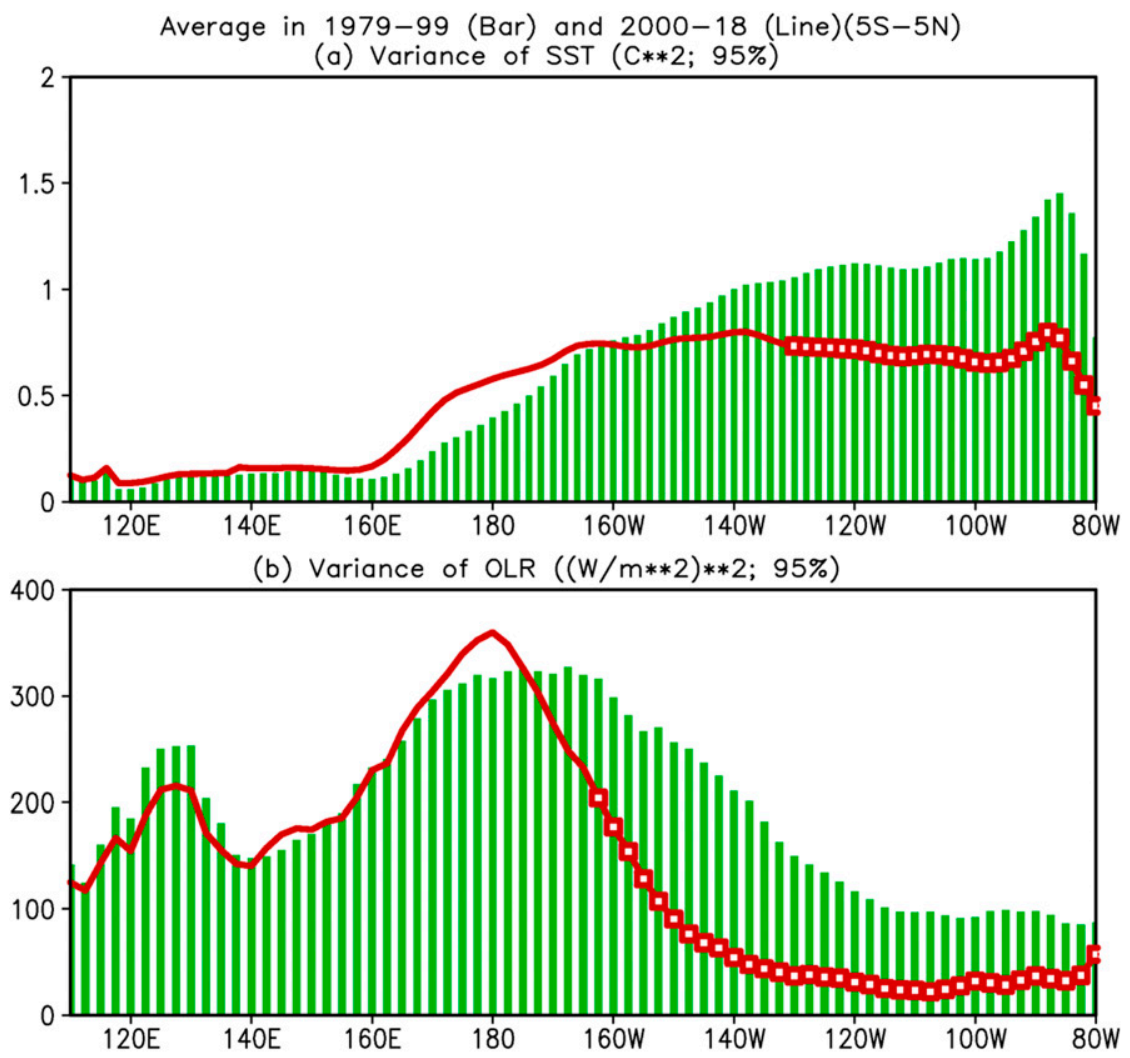

(c) $1000 \mathrm{hPa}$ westerly wind energy (u*u; R2, $6 \mathrm{hr},(\mathrm{m} / \mathrm{s}) * * 2$ )

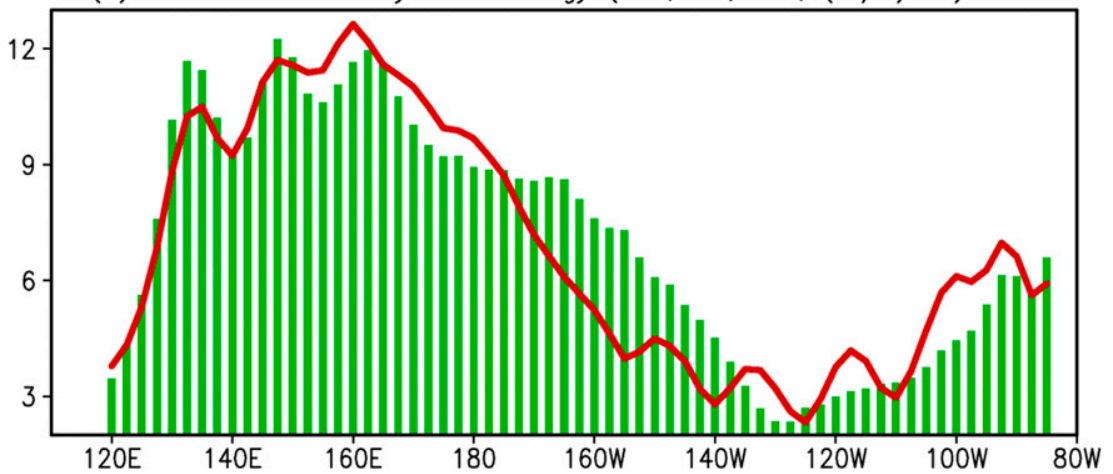

FIG. 8. Longitude-dependent variance of (a) monthly mean SSTA $\left({ }^{\circ} \mathrm{C}^{2}\right)$, (b) monthly mean OLR anomaly $\left[\left(\mathrm{W} \mathrm{m}^{-2}\right)^{2}\right]$, and (c) westerly wind energy $\left[\left(\mathrm{m} \mathrm{s}^{-1}\right)^{2}\right.$; referred to as $u^{2}$ and $\left.u>0.0\right]$ averaged in $5^{\circ} \mathrm{S}-5^{\circ} \mathrm{N}$ in January 1979-December 1999 (bars) and in January 2000-December 2018 (curve). The zonal wind refers to the 6-hourly mean zonal wind at $1000 \mathrm{hPa}$. The curve with open squares in (a) and (b) indicates when the change of the variance is significant at the 95\% significance level using an $F$ test based on 1000 Monte Carlo resamples. Replotted with updated data after Li et al. (2019a).

Lübbecke and McPhaden 2014). Recently, Li et al. (2019a) showed a statistical association between the anomalous SST zonal gradient across the tropical Pacific and the longitudinal location of maximum SSTA along the equator in observations. They noted that maximum positive SSTA along the equator in the Pacific is more likely shifted to the west when the gradient of SSTA between the western and eastern equatorial Pacific increases. The enhanced zonal contrast of the mean states along the equator and westward shift of climate variability in the tropical Pacific after 2000 fit this statistical description. Such mean state changes may also lead to a change of the ENSO flavors, which in turn reflect a change in the ENSO variability (Timmermann et al. 2018). For example, the mean characteristics in both pre-1973 and post-1998 periods were a La Niña-like condition with the westward 

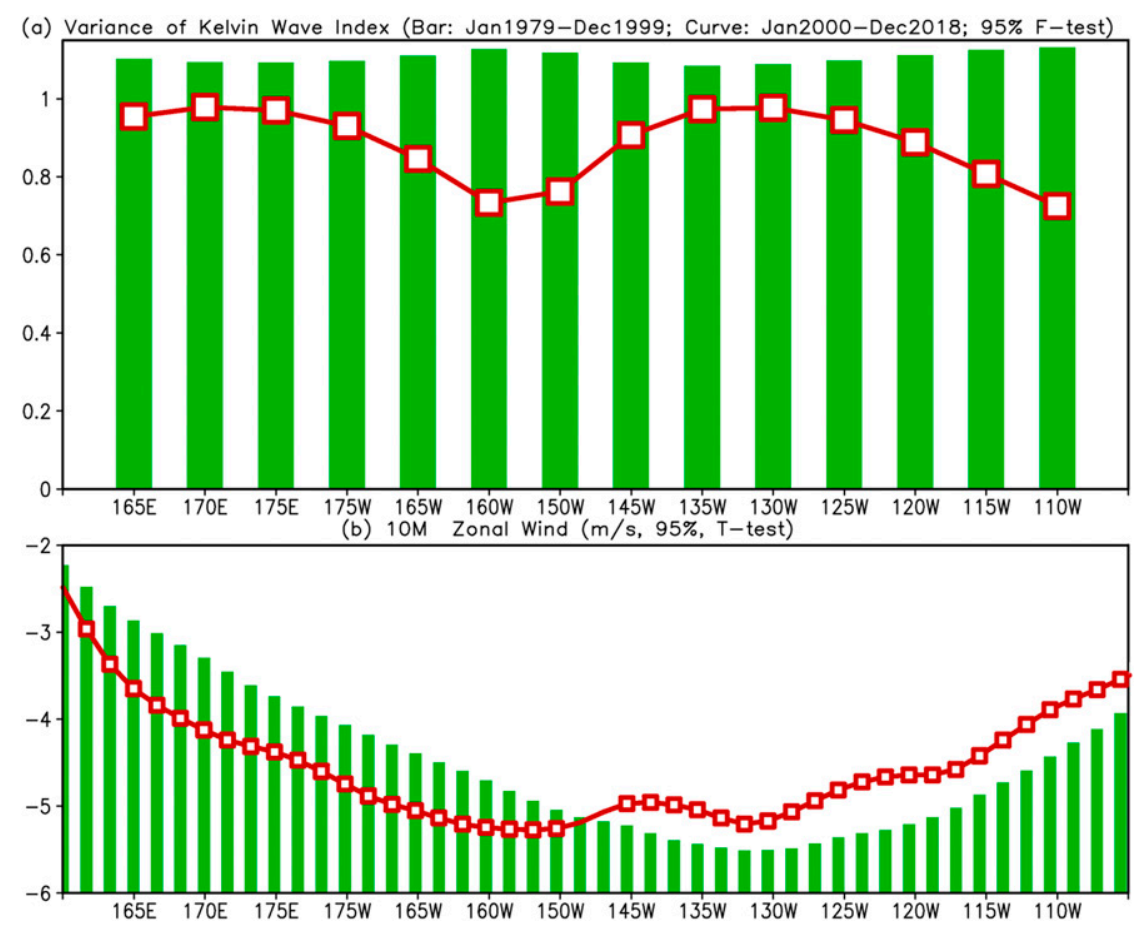

FIG. 9. Longitude-dependent (a) variance of pentad Kelvin wave index $\left({ }^{\circ} \mathrm{C}\right)$ and (b) monthly

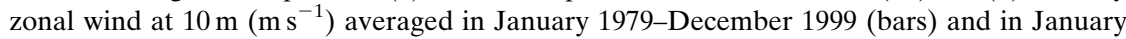
2000-December 2018 (curve). The curve with open squares in (a) indicates when the change of the variance is significant at the $95 \%$ significance level using an $F$ test based on 1000 Monte Carlo resamples, and the curve with open squares in (b) represents that the difference of the zonal wind at $10 \mathrm{~m}$ is significant at the $95 \%$ significance level using a $t$ test.

displacement of atmosphere-ocean coupling (Bunge and Clarke 2014). That is unfavorable for the development of the canonical (EP) El Niño and suppresses ENSO-related tropical Pacific variability.

The interdecadal variations are also shown in oceanic Kelvin wave activity (Fig. 9) at different longitudes along the equator in 1979-99 and 2000-18 (Seo and Xue 2005). During 1979-99, the variance of the oceanic Kelvin waves does not vary notably with longitude. However, that is not the case during 2000-18 (curve in Fig. 9a). In the background of overall ENSO weakening, the reduction of Kelvin wave variance is significant at the $95 \%$ level during 2000-18 compared with that during 1979-99 (Fig. 9a). The significant decline of the Kelvin wave variance reflects reduced Kelvin wave activity along the equatorial Pacific after 2000 (Fig. 9a), which coincides with the strengthening (weakening) of the mean trade winds east (west) of $140^{\circ} \mathrm{W}$ along the equator (Fig. 9b). The decline of the Kelvin wave variance $175^{\circ}-145^{\circ} \mathrm{W}$ (Fig. 9a) may be associated with the weakening of higher-frequency, low-level westerly winds in the same longitude belt (Fig. 8c). That is consistent with Harrison and Chiodi (2009). They noted that the influence of WWEs in the western equatorial Pacific with warming of SST in the eastern equatorial Pacific weakened post-1997/98 and argued that the wind differences can account for the changes in the average cold tongue warming associated with pre- and post-1997/98 WWEs.

Recently, Hu and Fedorov (2018) proposed that crossequatorial meridional wind may be associated with ENSO variability and the longitudinal location of atmosphereocean coupling. They argued that observed southerly wind trends in the eastern tropical Pacific led to a suppression of ENSO variability and westward shift of the tropical Pacific atmosphere-ocean coupling. The southerly wind trends during 1982-2015 appears to be linked to a Pacific meridional mode-like (Chiang and Vimont 2004) or North Pacific mode-like (Peng et al. 2018) SSTA pattern in the eastern tropical Pacific, as well as a warming trend in the tropical North Atlantic Ocean. Moreover, the whitening of ENSO frequency (Fig. 6) may be associated with an increase of the influence of seasonal footprinting mechanism (subtropical forcing) on ENSO during the last two decades, leading to a less cyclic ENSO evolution (Yu and Fang 2018).

Notably, the ENSO regime shift around 1999/2000 is opposite to that around 1976/77. The shift around 1976/ 77 featured an increase of ENSO variability and a 


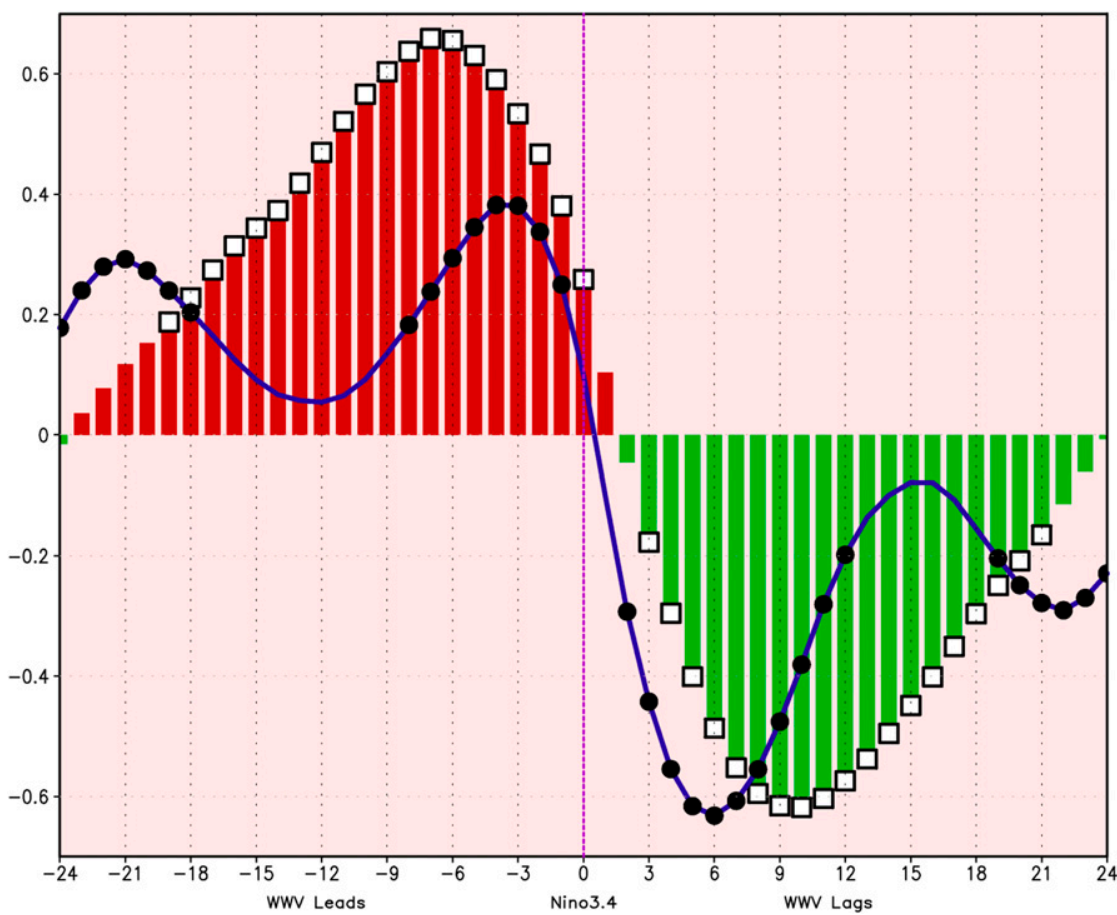

FIG. 10. Lead and lag correlations between the Niño-3.4 and WWV indices in January 1979December 1999 (bars), and January 2000-December 2018 (curve). The negative (positive) numbers on the $x$ axis represent the number of months that the WWV index leads (lags) the Niño-3.4 index. The bars with squares and the curve segments with closed circles represent significant correlations at the $99 \%$ significance level using a $t$ test. Replotted with updated data after McPhaden (2012) and Hu et al. (2017a,c).

decrease of frequency, which was linked to a reduction of the mean state contrast across the tropical Pacific and an eastward shift of atmosphere-ocean coupling (Wang 1995; Kirtman and Schopf 1998; An and Wang 2000). Similar changes in both ENSO characteristics and mean state in the tropical Pacific occurred around 1999/2000, but of opposite sign to the 1976/77 shift. This implies that similar mechanisms may have played a role in the two regime shifts.

\section{Consequences and impacts on seasonal climate prediction}

It is likely that changes in ENSO properties would affect not only ENSO prediction but also subseasonalto-seasonal climate predictions due to their dependence on ENSO (Cai et al. 2019). A consequence of the frequency changes in the Niño-3.4 and WWV indices are reflected in the lead-lag correlations between the two indices in the periods before and after 2000 (Fig. 10). The WWV led Niño-3.4 by 7-8 months during 1979-99 but only 3-4 months during 2000-18. The maximum correlation coefficients also decreased in the latter period, which is consistent with the results of McPhaden
(2012), Horii et al. (2012), and Kumar and Hu (2014a). The decline in the lead time, together with the suppression of ENSO variability, reduces the usefulness of WWV as a predictor for ENSO after 2000, although the recharge-discharge processes still controlled ENSO evolution to some extent (Clarke and Gorder 2001, 2003; Chen et al. 2004; Kug et al. 2005; Clarke et al. 2007; Wen et al. 2014; Neske and McGregor 2018; Planton et al. 2018; Clarke and Zhang 2019).

Bunge and Clarke (2014) point out that the decreased lead time is related to an increase of the variance in the tilt (east-west dipole) mode of thermocline variations and a decrease in the amplitude of the WWV mode. The WWV mode represents heat recharge and discharge processes integrated over the entire equatorial band of the Pacific (Jin 1997a,b; Meinen and McPhaden 2000; Clarke 2010; Kumar and Hu 2014a). By decomposing the equatorial Pacific WWV into the adjusted wind response (predictable) and instantaneous wind response (unpredictable) components, Neske and McGregor (2018) note that instantaneous contribution increased and adjusted contribution decreased in association with the post-2000 reduction in WWV and SST lead times. The change of the relative weights between the two 
(a) Lead 1 Month

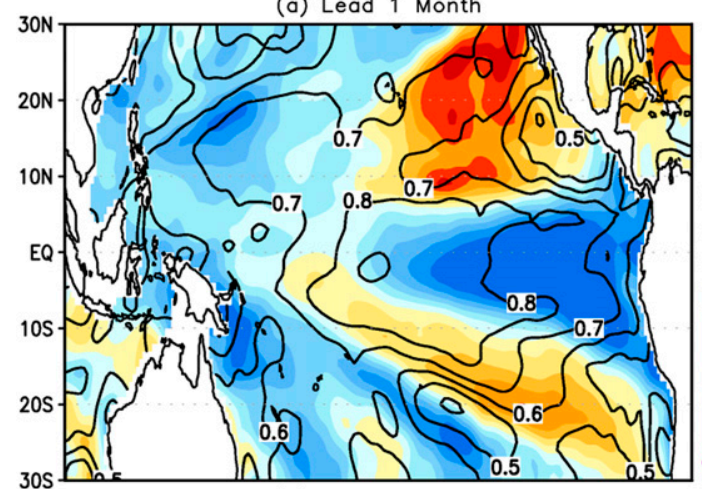

(c) Lead 5 Month

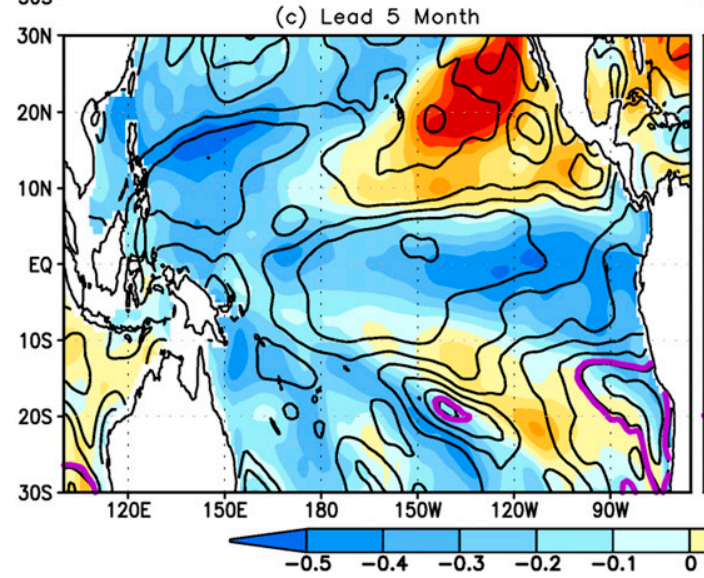

FIG. 11. Correlations between observed and CFSv2-predicted monthly SSTAs with ICs in January 1982 December 2018 (contours) and the differences of the correlations with ICs in January 2000-December 2018 and in January 1982-December 1999 (shading) at (a) 1-, (b) 3-, (c) 5-, and (d) 7-month leads. The purple contours represent the significance of the correlations in January 1982-December 2018 at the $99 \%$ significance level using a $t$ test. Contour and shading intervals are 0.1 . The CFSv2 predictions are the ensemble mean of 20 members. contributions implies a smaller role for the recharge processes in the evolution of ENSO post-2000. According to Jin (1997a,b), the recharge/discharge paradigm seems to dictate a time scale of the ENSO cycle with 3-5 years. Thus, the less effective recharge/discharge process in the latter period (Guan and McPhaden 2016) may be associated with increase of ENSO frequency.

It is also interesting that the lag time of the maximum negative correlation in the WWV index relative to the Niño-3.4 index changed from 9-10 months in 1979-99 to 5-6 months in 2000-18 (Fig. 10). This is consistent with the regime shift of ENSO from low frequency in 1979-99 to high frequency in 2000-18 (Fig. 6). On the other hand, the amplitude of the correlation is comparable between the two periods when the WWV index lags the Niño3.4 index.

The regime shift around 1999/2000 toward a higher ENSO frequency and smaller variability, as well as a shorter lead time of the WWV index relative to the Niño-3.4 index and weaker correlation between the indices, means that ocean precursors became less effective for ENSO forecasting after 2000. This contributes to a reduction in inherent predictability and skill of ENSO (Wang et al. 2010; Barnston et al. 2012; Zhao et al. 2016; Newman and Sardeshmukh 2017). Such a decline of prediction skill usually occurs during periods of lower ENSO variance, which is a key determinant in the signalto-noise ratio (Kumar and Hoerling 2000; Kumar and $\mathrm{Hu}$ 2014b; Hu et al. 2019). The decline of prediction skill is consistent with the increasing frequency of CP El Niño events and the decreasing frequency of EP El Niño events in recent decades (Yeh et al. 2009; Capotondi et al. 2015). Compared with EP events, CP events have weaker atmospheric and oceanic coupling and smaller amplitude (signal). Thus, CP events are less predictable (Hendon et al. 2009; Fig. 13 of Hu et al. 2012a; Capotondi et al. 2015; Zheng and Yu 2017).

Using CFSv2 as an example, Fig. 11 shows the mean forecast skill of SSTA in the tropical Pacific based on starting conditions between January 1982 and December 2018 (contour) and the differences in skill between January 1982-December 1999 and January 2000-December 2018 

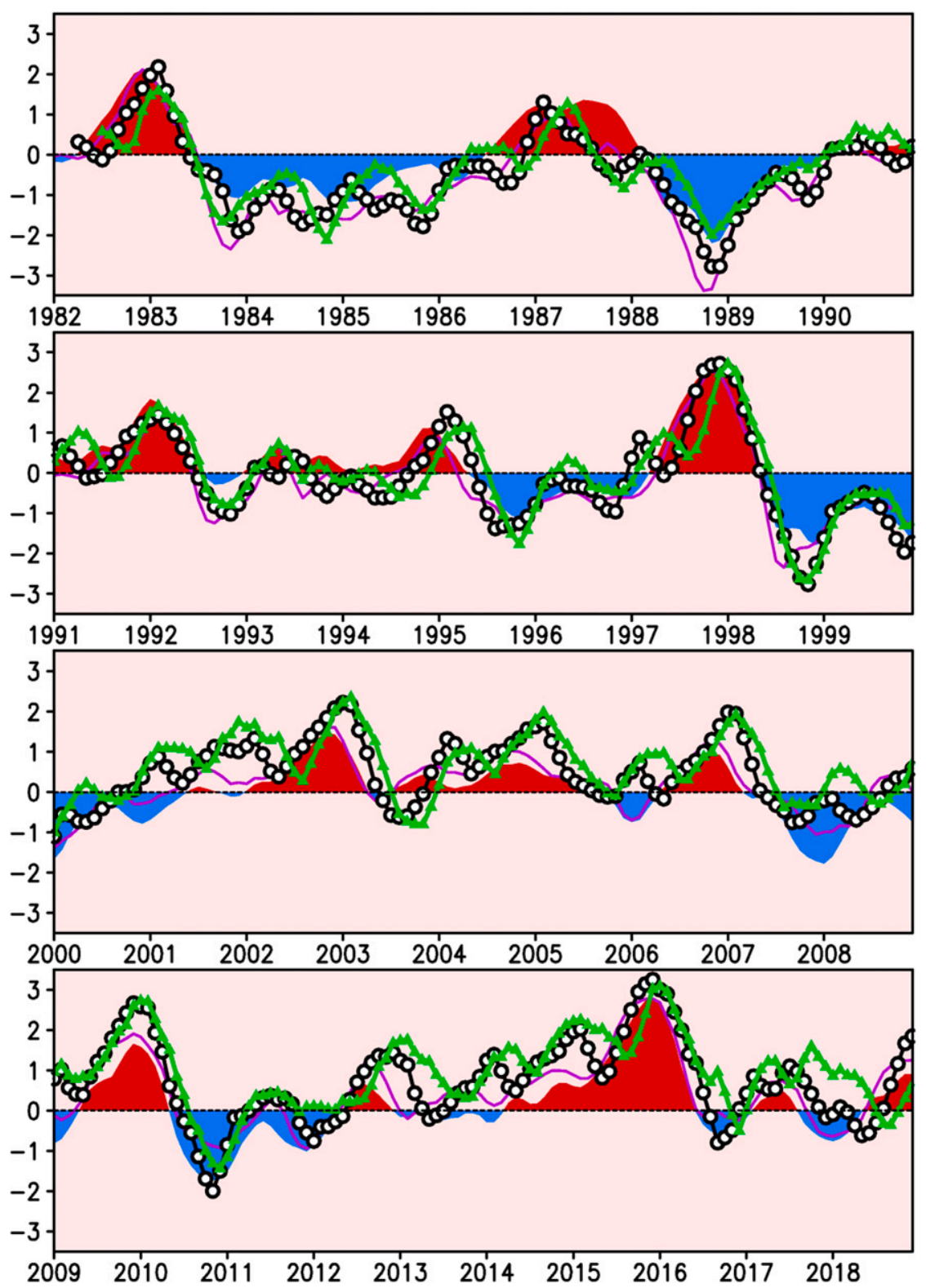

FIG. 12. Observed (shading) and CFSv2-predicted Niño-3.4 index $\left({ }^{\circ} \mathrm{C}\right)$ in January 1982 December 2018. The predictions of 1-, 4-, and 7-month leads are represented by purple lines, black lines with open circles, and green lines with closed triangle curves, respectively. The CFSv2 predictions are the ensemble mean of 20 members.

(shading). The climatology of the mean and standard deviation is based on 1982-2018. The maximum mean forecast skill is in the central-eastern tropical Pacific Ocean (Fig. 11) with skill declining with lead time. The skill differences show a pronounced decrease over most of the tropical Pacific, although some increases are present in the northeastern and southern tropical Pacific. The decrease is most remarkable in the eastern tropical Pacific, which may be linked to the weakening of atmosphereocean coupling in the region (Figs. 2, 3, 7, and 8).
Another possible consequence of the shorter ENSO period after 2000 is that the forecast peaks of SSTA often lag the observed by several months, and the lag increases as the lead time increases (Fig. 12). The forecasted peaks sometime lag or sometime lead the corresponding observed peak during 1982-99, whereas no forecasted peaks precede the corresponding observed ones during 2000-18. That is particularly evident for the La Niña in 2011/12 and for the positive Niño-3.4 index values in 2012 and 2017. In fact, this seems to be a 


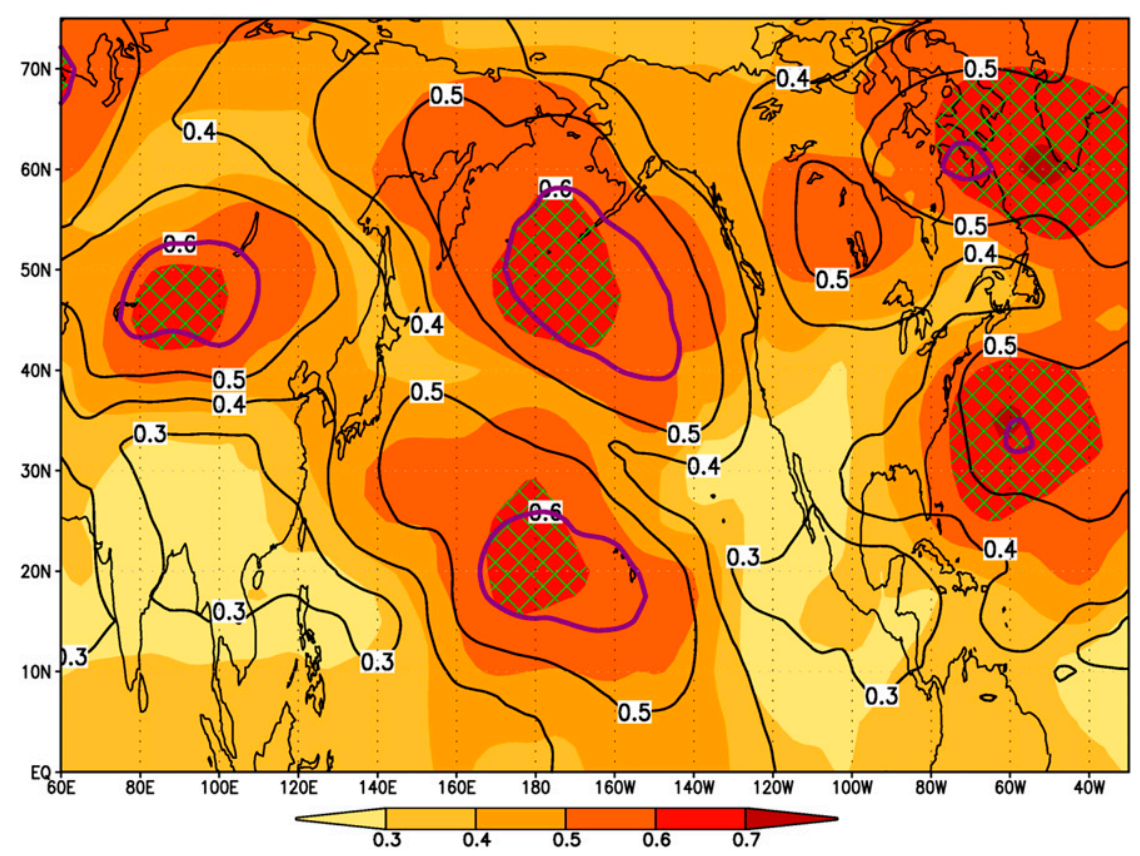

FIG. 13. Teleconnectivity of H500 in January 1979-December 1999 (contours) and January 2000-December 2018 (shading). Contour and shading intervals are 0.1. The hatched regions represent the shading values larger than 0.6 , and the purple contour is 0.6 .

common phenomenon for most dynamical forecasts collected by International Research Institute for Climate and Society (Barnston et al. 2012; Barnston 2014). This phenomenon has been called "target period slippage" by Barnston et al. (2012) and is also discussed in Tippett et al. (2012). We speculate that the slippage occurs because these models were developed based on ENSO features from an earlier period with relatively low frequency, but when ENSO frequency increased after 2000, the models were not able to adjust.

The ENSO regime shift may have also altered ENSO's impacts on the extratropics. To examine the impact on the extratropics, the teleconnectivity of $500-\mathrm{hPa}$ geopotential height is calculated following Wallace and Gutzler (1981). The teleconnectivity of a base point is defined as the absolute value of the largest negative value among the temporal correlations between the base point and the other points on the globe. The teleconnection pattern in the Asia-Pacific-North America section mainly reflects a Pacific-North American (PNA) pattern (Fig. 13). Compared with 1979-99, the centers of the teleconnection over the Pacific shifted northwestward in 2000-18. Such a PNA-like teleconnection pattern is at least partially associated with the tropical forcing (Wallace and Gutzler 1981; Li et al. 2019c) and thus this northwestward shift may be associated with a westward shift of the atmosphere-ocean coupling in the tropical Pacific after 2000 shown in Figs. 7 and 8
(Hu et al. 2017a; Li et al. 2019a), due to the sensitivity of an extratropical response to the location of tropical forcing (e.g., Ting and Sardeshmukh 1993; Schneider et al. 2003; Zhang et al. 2016; Yeh et al. 2018). Thus, the interdecadal shift of ENSO properties may affect the predictability and prediction skill in the extratropics (Kumar et al. 2010; Deser et al. 2010). It is also noted that the teleconnection patterns are based on the analysis over a short observational record, and therefore could also be influenced by factors other than ENSO, such as variability driven by atmospheric internal dynamical processes.

\section{Summary and future challenges}

After the interdecadal shift in 1976/77, another regime shift occurred in 1999/2000 that featured a decrease in the variability and an increase in the frequency of ENSO. These changes are associated with an enhanced zonal gradient of SST across the tropical Pacific as well as a more stable tropospheric atmosphere along the equator since 1999/2000. The observations show that the warming trends are larger in the midtroposphere than the low troposphere over the equatorial Pacific, leading to a more stable troposphere (Hu et al. 2017b). The stable atmosphere suppresses the deep convection that may lead to weakening the atmosphere and ocean coupling and to reducing the amplitude of ENSO. 
Meanwhile, the peak period of the Niño-3.4 index shifted from 1.5-5 years during 1979-99 to around 1.53.5 years during $2000-18$, along with a flatter variance distribution. The frequency spectrum of WWV had almost no peak in 2000-18, implying a nearly white noise process. The increased frequency of ENSO may be linked to a westward shift in the zone of atmosphere-ocean coupling in the tropical Pacific since 1999/2000. The observed westward shift of the wind stress anomalies reduces the growth of coupled mode and advances the transition of the ENSO cycles, thus resulting in a shorter period with a smaller amplitude according to An and Wang (2000).

One of the consequences of these changes is a decrease in ENSO prediction skill (Wang et al. 2010; Barnston et al. 2012). The whitening of the frequency in upper ocean heat content (as measured by the WWV index) led to a breakdown of the relationship between WWV and ENSO (e.g., McPhaden 2012), implying the reduced utility of WWV as a key predictor for ENSO. Another consequence, which is related to a shorter ENSO period, is that the forecasted peaks in SSTA often lagged the observed peaks by several months (Fig. 12). This so-called target period slippage (also see Fig. 12 of Barnston et al. 2012) increased with lead time. This error in prediction implies that the state-of-the-art climate models did not properly capture the interdecadal shift in the frequency of ENSO. Thus, both the regime shift of ENSO in 1999/2000 and the model default may account for ENSO prediction skill decrease skill since 1999/2000. Moreover, the regime shift and reduced predictability of ENSO may also have altered ENSO's impacts on the extratropics, implying additional challenges for seasonal climate predictions (McPhaden 2015).

The nature of the relationship between ENSO changes and mean state changes is still under debate. Some studies emphasize the influence of the mean state change on ENSO (Wang and An 2002; Fang et al. 2008). While others argue that the low-frequency intrinsic variation of ENSO contributes to the mean state changes, instead of the other way around. For example, Vimont (2005) noted that prominent spatial features of decadal ENSO-like variability are generated by physical mechanisms that operate through the interannual ENSO cycle. The irregularity of ENSO variations as well as the asymmetric features of El Niño and La Niña were argued to be linked to the interdecadal shifts in the tropical Pacific (Schopf and Burgman 2006; Sun and Yu 2009; McPhaden et al. 2011; Ogata et al. 2013; Rodgers et al. 2004; Okumura et al. 2017). Examining the dominant structures of the ENSO evolution using the observations in 1958-77 and 1978-97, Capotondi and Sardeshmukh (2017) showed that statistically significant changes in ENSO dynamics occurred between the two periods. They suggest that ENSO dynamics in the later period were consistent with the reduced zonal slope of the mean thermocline; however, the mean thermocline change may also be a consequence of the amplitude asymmetry between the warm and cold events. We argued that a similar change of the ENSO dynamics (but with opposite sign) occurred around 1999/2000. In addition, the extratropical Pacific (Okumura 2013; Zhang et al. 2014; Ding et al. 2015, 2017; Di Lorenzo et al. 2015; Yu and Fang 2018; Sun and Okumura 2019), the Indian Ocean (e.g., Luo et al. 2012), and the Atlantic Ocean (e.g., Ham et al. 2013; Yu et al. 2015; Li et al. 2016; Wang et al. 2017; Cai et al. 2019) may also connect with the interdecadal shifts of the mean state in the tropical Pacific Ocean.

Another question is whether the ENSO regime shift is a reflection of natural variability or anthropogenic forced variations, or a combination of the two. Previous work documented the possible impact of increasing greenhouse gas (GHG) concentrations on the tropical Pacific climate and ENSO. Model simulations, in response to rising GHG concentrations, include weaker mean easterly trade winds in the Pacific, shoaling of the equatorial thermocline, and enhanced oceanic temperature vertical gradients across the thermocline (Guilyardi et al. 2009; Collins et al. 2010). Such mean state changes may alter ENSO variability (Meehl and Washington 1996; Timmermann et al. 1999; Hu et al. 2000, 2012b; Cai et al. 2014). However, projected changes from GHG forcing vary from model to model, with some projecting an increase and others a decrease in ENSO variability $(\mathrm{Hu}$ et al. 2012b; Cai et al. 2015, 2018). Differences in the projections may partially reflect the errors in the models or the influence of competing mechanisms that will ultimately determine how ENSO might change. Furthermore, climate models still struggle to represent diversity/ flavors of ENSO in observations (e.g., Bellenger et al. 2013; Capotondi et al. 2015; Timmermann et al. 2018). For example, Jha et al. (2014) show that in historical runs of phase 5 of the Coupled Model Intercomparison Project (CMIP5), some models are unable to capture the spatial pattern of SST variability associated with ENSO and most models are unable to simulate the spectral characteristics of ENSO realistically.

In fact, the observed mean state changes in the equatorial Pacific from 1979-99 to 2000-18 discussed herein have some clear differences with the mean of model projections under various global warming scenarios (Collins et al. 2010; McPhaden et al. 2011; England et al. 2014; Hu et al. 2016, 2017a). Such disagreements may suggest that observed mean state change is partly associated with internal low-frequency variations of the atmosphere-ocean coupled system (Wittenberg 2009; Hu et al. 2012a). By analyzing a 2000-yr coupled model run with atmospheric composition, solar irradiance, and land cover fixed at the 1860 
values, Wittenberg (2009) identified strong interdecadal and intercentennial modulations of ENSO and noted that ENSO variance can change by $100 \%$ from period to period entirely due to natural causes. This implies that the internal processes of the atmosphere-ocean coupled system can generate remarkable modulations in the tropical Pacific climate, including changes in its mean state and variability (Deser et al. 2012).

It is obvious that the data are too short to definitively attribute the reasons behind the observed interdecadal shift. That brings up the necessity of using paleoclimate data or other targeted model simulations to examine if the dynamical mechanisms based on the regime shifts can be replicated and better understood. Nevertheless, the consistency of the results analyzed in this work from various atmospheric and oceanic variables and from different sources (analyses and reanalyses) provides solid evidences for the occurrence of the interdecadal shift of ENSO regime around 1999/2000 and the associated mechanisms discussed in this work.

Acknowledgments. We appreciated the insightful and constructive comments and suggestions of three reviewers as well as our colleagues, Drs. Emily Becker, Hui Wang, and Chidong Zhang. The hindcast and real-time forecast data at NCEP/CPC were archived and maintained by Dr. Wanqiu Wang. Bohua Huang is supported by grants from NSF (AGS-1338427), NASA (NNX14AM19G), and NOAA (NA14OAR4310160 and NA17OAR4310144). The scientific results and conclusions, as well as any view or opinions expressed herein, are those of the authors and do not necessarily reflect the views of NWS, NOAA, or the Department of Commerce. This is PMEL contribution number 5014.

\section{REFERENCES}

An, S.-I., and B. Wang, 2000: Interdecadal change of the structure of the ENSO mode and its impact on the ENSO frequency. J. Climate, 13, 2044-2055, https://doi.org/10.1175/1520-0442(2000) 013<2044:ICOTSO > 2.0.CO;2.

Balmaseda, M. A., M. K. Davey, and D. L. T. Anderson, 1995: Decadal and seasonal dependence of ENSO prediction skill. J. Climate, 8, 2705-2715, https://doi.org/10.1175/1520-0442(1995) 008<2705:DASDOE $>2.0 . \mathrm{CO} ; 2$.

Barnston, A. G., 2014: How good have ENSO forecasts been lately? ENSO blog, accessed 26 August 2019, https:// www.climate.gov/news-features/blogs/enso/how-good-haveenso-forecasts-been-lately.

—, M. K. Tippett, M. L. L'Heureux, S. Li, and D. G. DeWitt, 2012: Skill of real-time seasonal ENSO model predictions during 2002-2011: Is our capability increasing? Bull. Amer. Meteor. Soc., 93, 631-651, https://doi.org/10.1175/BAMS-D-11-00111.1.

Behringer, D. W., 2007: The Global Ocean Data Assimilation System (GODAS) at NCEP. 11th Symp. on Integrated Observing and Assimilation Systems for Atmosphere, Oceans, and
Land Surface, San Antonio, TX, Amer. Meteor. Soc., 3.3, http:// ams.confex.com/ams/87ANNUAL/techprogram/paper_119541.htm.

Bellenger, H., E. Guilyardi, J. Leloup, M. Lengaigne, and J. Vialard, 2013: ENSO representation in climate models: From CMIP3 to CMIP5. Climate Dyn., 42, 1999-2018, https://doi.org/10.1007/ s00382-013-1783-z.

Bunge, L., and A. J. Clarke, 2014: On the warm water volume and its changing relationship with ENSO. J. Phys. Oceanogr., 44, 1372-1385, https://doi.org/10.1175/JPO-D-13-062.1.

Cai, W., and Coauthors, 2014: Increasing frequency of extreme El Niño events due to greenhouse warming. Nat. Climate Change, 4, 111-116, https://doi.org/10.1038/nclimate2100.

—, and Coauthors, 2015: ENSO and greenhouse warming. Nat. Climate Change, 5, 849-859, https://doi.org/10.1038/nclimate2743.

_- and Coauthors, 2018: Increased variability of eastern Pacific El Niño under greenhouse warming. Nature, 564, 201-206, https://doi.org/10.1038/s41586-018-0776-9.

- , and Coauthors, 2019: Pantropical climate interactions. Science, 363, eaav4236, https://doi.org/10.1126/science.aav4236.

Cane, M., S. E. Zebiak, and S. C. Dolan, 1986: Experimental forecasts of El Niño. Nature, 321, 827-832, https://doi.org/ 10.1038/321827a0.

Capotondi, A., and P. D. Sardeshmukh, 2017: Is El Niño really changing? Geophys. Res. Lett., 44, 8548-8556, https://doi.org/ 10.1002/2017GL074515.

_ - and Coauthors, 2015: Understanding ENSO diversity. Bull. Amer. Meteor. Soc., 96, 921-938, https://doi.org/10.1175/BAMSD-13-00117.1.

Chen, D., M. A. Cane, A. Kaplan, S. E. Zebiak, and D. J. Huang, 2004: Predictability of El Niño over the past 148 years. Nature, 428, 733-736, https://doi.org/10.1038/nature02439.

_ , and Coauthors, 2015: Strong influence of westerly wind bursts on El Niño diversity. Nat. Geosci., 8, 339-345, https://doi.org/ 10.1038/ngeo2399.

Chiang, J. C. H., and D. J. Vimont, 2004: Analogous Pacific and Atlantic meridional modes of tropical atmosphere-ocean variability. J. Climate, 17, 4143-4158, https://doi.org/10.1175/JCLI4953.1.

Clarke, A. J., 2010: Analytical theory for the quasi-steady and lowfrequency equatorial ocean response to wind forcing: The "tilt" and "warm water volume" modes. J. Phys. Oceanogr., 40, 121-137, https://doi.org/10.1175/2009JPO4263.1.

_ 2014: El Niño physics and El Niño predictability. Annu. Rev. Mar. Sci., 6, 79-99, https://doi.org/10.1146/annurev-marine010213-135026.

— trigger and a proxy for western equatorial Pacific warm pool movement. Geophys. Res. Lett., 28, 579-582, https://doi.org/ 10.1029/2000GL012201.

— time integration of Indo-Pacific winds and equatorial Pacific upper ocean heat content. Geophys. Res. Lett., 30, 1399, https://doi.org/10.1029/2002GL016673.

_ ume and El Niño/La Niña predictability. J. Phys. Oceanogr., 49, 1541-1560, https://doi.org/10.1175/JPO-D-18-0144.1.

_ S. Van Gorder, and G. Colantuono, 2007: Wind stress curl and ENSO discharge/recharge in the equatorial Pacific. J. Phys. Oceanogr., 37, 1077-1091, https://doi.org/10.1175/JPO3035.1.

Collins, M., and Coauthors, 2010: The impact of global warming on the tropical Pacific Ocean and El Niño. Nat. Geosci., 3, 391397, https://doi.org/10.1038/ngeo868.

Deser, C., A. S. Phillips, and M. A. Alexander, 2010: Twentieth century tropical sea surface temperature trends revisited. 
Geophys. Res. Lett., 37, L10701, https://doi.org/10.1029/ 2010GL043321.

— - — , V. Bourdette, and H. Teng, 2012: Uncertainty in climate change projections: The role of internal variability. Climate Dyn., 38, 527-546, https://doi.org/10.1007/s00382-010-0977-x.

Di Lorenzo, E., G. Liguori, N. Schneider, J. C. Furtado, B. T. Anderson, and M. A. Alexander, 2015: ENSO and meridional modes: A null hypothesis for Pacific climate variability. Geophys. Res. Lett., 42, 9440-9448, https://doi.org/10.1002/ 2015GL066281.

Ding, R. Q., J. P. Li, and Y. H. Tseng, 2015: The impact of South Pacific extratropical forcing on ENSO and comparisons with the North Pacific. Climate Dyn., 44, 2017-2034, https://doi.org/ 10.1007/s00382-014-2303-5.

,,,--- C. Sun, and F. Xie, 2017: Joint impact of North and South Pacific extratropical atmospheric variability on the onset of ENSO events. J. Geophys. Res. Atmos., 122, 279-298, https://doi.org/10.1002/2016JD025502.

England, M. H., and Coauthors, 2014: Recent intensification of wind-driven circulation in the Pacific and the ongoing warming hiatus. Nat. Climate Change, 4, 222-227, https://doi.org/ 10.1038/nclimate2106.

Fang, Y., J. C. Chiang, and P. Chang, 2008: Variation of mean sea surface temperature and modulation of El Niño-Southern Oscillation variance during the past 150 years. Geophys. Res. Lett., 35, L14709, https://doi.org/10.1029/2008GL033761.

Fedorov, A. V., and S. G. Philander, 2001: A stability analysis of tropical ocean-atmosphere interactions: Bridging measurements and theory for E1 Niño. J. Climate, 14, 3086-3101, https://doi.org/10.1175/1520-0442(2001)014<3086:ASAOTO > 2.0.CO;2.

Graham, R. J., and Coauthors, 2011: Long-range forecasting and the Global Framework for Climate Services. Climate Res., 47, 47-55, https://doi.org/10.3354/cr00963.

Guan, C., and M. J. McPhaden, 2016: Ocean processes affecting the twenty-first-century shift in ENSO SST variability. J. Climate, 29, 6861-6879, https://doi.org/10.1175/JCLI-D-15-0870.1.

Guilyardi, E., A. Wittenberg, A. Fedorov, M. Collins, C. Wang, A. Capotondi, G. J. van Oldenborgh, and T. Stockdale, 2009: Understanding El Niño in ocean-atmosphere general circulation models: Progress and challenges. Bull. Amer. Meteor. Soc., 90, 325-340, https://doi.org/10.1175/2008BAMS2387.1.

Ham, Y. G., J.-S. Kug, J.-Y. Park, and F.-F. Jin, 2013: Sea surface temperature in the north tropical Atlantic as a trigger for El Niño/Southern Oscillation events. Nat. Geosci., 6, 112-116, https://doi.org/10.1038/ngeo1686.

Harrison, D. E., and A. Chiodi, 2009: Pre- and post-1997/98 westerly wind events and equatorial Pacific cold tongue warming. J. Climate, 22, 568-581, https://doi.org/10.1175/2008JCLI2270.1.

Hendon, H. H., E. Lim, G. Wang, O. Alves, and D. Hudson, 2009: Prospects for predicting two flavors of El Niño. Geophys. Res. Lett., 36, L19713, https://doi.org/10.1029/2009GL040100.

Horii, T., I. Ueki, and K. Hanawa, 2012: Breakdown of ENSO predictors in the 2000s: Decadal changes of recharge/discharge-SST phase relation and atmospheric intraseasonal forcing. Geophys. Res. Lett., 39, L10707, https://doi.org/10.1029/2012GL051740.

$\mathrm{Hu}$, S., and A. V. Fedorov, 2018: Cross-equatorial winds control El Niño diversity and change. Nat. Climate Change, 8, 798-802, https://doi.org/10.1038/s41558-018-0248-0.

Hu, Z.-Z., and T. Nitta, 1996: Wavelet analysis of summer rainfall over North China and India and SOI using 1891-1992 data. J. Meteor. Soc. Japan, 74, 833-844, https://doi.org/10.2151/ jmsj1965.74.6_833.
_- M. Latif, E. Roeckner, and L. Bengtsson, 2000: Intensified Asian summer monsoon and its variability in a coupled model forced by increasing greenhouse gas concentrations. Geophys. Res. Lett., 27, 2681-2684, https://doi.org/10.1029/2000GL011550.

- A. Kumar, B. Jha, W. Wang, B. Huang, and B. Huang, 2012a: An analysis of warm pool and cold tongue El Niños: Air-sea coupling processes, global influences, and recent trends. Climate Dyn., 38, 2017-2035, https://doi.org/10.1007/s00382-011-1224-9.

,,--- , and B. Huang, 2012b: An analysis of forced and internal variability in a warmer climate in CCSM3. J. Climate, 25, 2356-2373, https://doi.org/10.1175/JCLI-D-11-00323.1.

, - - H.-L. Ren, H. Wang, M. L'Heureux, and F.-F. Jin, 2013: Weakened interannual variability in the tropical Pacific Ocean after 2000. J. Climate, 26, 2601-2613, https://doi.org/10.1175/ JCLI-D-12-00265.1.

,-- , and B. Huang, 2016: Spatial distribution and the interdecadal change of leading modes of heat budget of the mixed-layer in the tropical Pacific and the association with ENSO. Climate Dyn., 46, 1753-1768, https://doi.org/10.1007/ s00382-015-2672-4.

,,,--- J. Zhu, and H.-L. Ren, 2017a: Interdecadal variations of ENSO around 1999/2000. J. Meteor. Res., 31, 73-81, https://doi.org/10.1007/s13351-017-6074-x.

_- B. Huang, Y. Tseng, W. Wang, A. Kumar, J. Zhu, and B. Jha, 2017b: Does vertical temperature gradient of the atmosphere matter for El Niño development? Climate Dyn., 48, 14131429, https://doi.org/10.1007/s00382-016-3149-9.

, A. Kumar, J. Zhu, B. Huang, Y. Tseng, and X. Wang, 2017c: On the shortening of the lead time of ocean warm water volume to ENSO SST since 2000. Sci. Rep., 7, 4294, https:// doi.org/10.1038/s41598-017-04566-z.

_ _ _ B. Jha, J. Zhu, and B. Huang, 2017d: Persistence and predictions of the remarkable warm anomaly in the northeastern Pacific Ocean during 2014-16. J. Climate, 30, 689-702, https://doi.org/10.1175/JCLI-D-16-0348.1.

,,-- J. Zhu, P. Peng, and B. Huang, 2019: On the challenge for ENSO cycle prediction: An example from NCEP Climate Forecast System version 2. J. Climate, 32, 183-194, https:// doi.org/10.1175/JCLI-D-18-0285.1.

-, , B. Jha, and B. Huang, 2020: How much of monthly mean precipitation variability over global land is associated with SST anomalies? Climate Dyn., 54, 701-712, https:// doi.org/10.1007/s00382-019-05023-5.

Huang, B., and Coauthors, 2017a: Extended Reconstructed Sea Surface Temperature, version 5 (ERSSTv5): Upgrades, validations, and intercomparisons. J. Climate, 30, 8179-8205, https://doi.org/10.1175/JCLI-D-16-0836.1.

, C.-S. Shin, J. Shukla, L. Marx, M. Balmaseda, S. Halder, P. A. Dirmeyer, and J. L. Kinter III, 2017b: Reforecasting the ENSO events in the past 57 years (1958-2014). J. Climate, 30, 7669-7693, https://doi.org/10.1175/JCLI-D-16-0642.1.

Jha, B., Z.-Z. Hu, and A. Kumar, 2014: SST and ENSO variability and change simulated in historical experiments of CMIP5 models. Climate Dyn., 42, 2113-2124, https://doi.org/10.1007/ s00382-013-1803-z.

Jin, F.-F., 1997a: An equatorial ocean recharge paradigm for ENSO. Part I: Conceptual model. J. Atmos. Sci., 54, 811-829, https://doi.org/10.1175/1520-0469(1997)054<0811:AEORPF $>$ 2.0.CO;2.

1997b: An equatorial ocean recharge paradigm for ENSO. Part II: A stripped-down coupled model. J. Atmos. Sci., 54, 830-847, https://doi.org/10.1175/1520-0469(1997)054<0830: AEORPF $>2.0 . \mathrm{CO} ; 2$. 
Kanamitsu, M., W. Ebisuzaki, J. Woollen, S.-K. Yang, J. J. Hnilo, M. Fiorino, and G. L. Potter, 2002: NCEP-DOE AMIP-II Reanalysis (R-2). Bull. Amer. Meteor. Soc., 83, 1631-1643, https://doi.org/10.1175/BAMS-83-11-1631.

Kao, H.-Y., and J.-Y. Yu, 2009: Contrasting eastern-Pacific and central-Pacific types of ENSO. J. Climate, 22, 615-632, https:// doi.org/10.1175/2008JCLI2309.1.

Kirtman, B., and P. S. Schopf, 1998: Decadal variability in ENSO predictability and prediction. J. Climate, 11, 2804-2822, https:// doi.org/10.1175/1520-0442(1998)011<2804:DVIEPA>2.0.CO;2.

_ and A. Pirani, 2009: The state of the art of seasonal prediction: Outcomes and recommendations from the First World Climate Research Program Workshop on seasonal prediction. Bull. Amer. Meteor. Soc., 90, 455-458, https://doi.org/10.1175/ 2008BAMS2707.1.

Kug, J.-S., S.-I. An, F.-F. Jin, and I.-S. Kang, 2005: Preconditions for El Niño and La Niña onsets and their relation to the Indian Ocean. Geophys. Res. Lett., 32, L05706, https://doi.org/10.1029/ 2004GL021674.

Kumar, A., and M. P. Hoerling, 2000: Analysis of a conceptual model of seasonal climate variability and implications for seasonal prediction. Bull. Amer. Meteor. Soc., 81, 255-264, https://doi.org/10.1175/1520-0477(2000)081<0255:AOACMO> 2.3.CO;2.

—_, and Z.-Z. Hu, 2014a: Interannual and interdecadal variability of ocean temperature along the equatorial Pacific in conjunction with ENSO. Climate Dyn., 42, 1243-1258, https:// doi.org/10.1007/s00382-013-1721-0.

$\longrightarrow$, and - 2014b: How variable is the uncertainty in ENSO sea surface temperature prediction? J. Climate, 27, 2779-2788, https://doi.org/10.1175/JCLI-D-13-00576.1.

— B. B. Jha, and M. L'Heureux, 2010: Are tropical SST trends changing the global teleconnection during La Niña? Geophys. Res. Lett., 37, L12702, https://doi.org/10.1029/ 2010 GL043394.

—, M. Chen, Y. Xue, and D. Behringer, 2015: An analysis of the temporal evaluation of ENSO prediction skill in the context of equatorial Pacific Ocean observing system. Mon. Wea. Rev., 143, 3204-3213, https://doi.org/10.1175/MWR-D-15-0035.1.

Latif, M., and Coauthors, 1998: A review of the predictability and prediction of ENSO. J. Geophys. Res., 103, 14375-14393, https://doi.org/10.1029/97JC03413.

Levine, A. F. Z., and M. J. McPhaden, 2016: How the July 2014 easterly wind burst gave the 2015-2016 El Niño a head start. Geophys. Res. Lett., 43, 6503-6510, https://doi.org/10.1002/ 2016 GL069204.

L'Heureux, M. L., S. Lee, and B. Lyon, 2013a: Recent multidecadal strengthening of the Walker circulation across the tropical Pacific. Nat. Climate Change, 3, 571-576, https://doi.org/ 10.1038/nclimate1840.

_ D. Dollins, and Z.-Z. Hu, 2013b: Linear trends in sea surface temperature of the tropical Pacific Ocean and implications for the El Niño-Southern Oscillation. Climate Dyn., 40, 1223 1236, https://doi.org/10.1007/s00382-012-1331-2.

—_ and Coauthors, 2017: Observing and predicting the 2015-16 El Niño. Bull. Amer. Meteor. Soc., 98, 1363-1382, https:// doi.org/10.1175/BAMS-D-16-0009.1.

, and Coauthors, 2019: Strength outlooks for the El NiñoSouthern Oscillation. Wea. Forecasting, 34, 165-175, https:// doi.org/10.1175/WAF-D-18-0126.1.

Li, X., S.-P. Xie, S. T. Gille, and C. Yoo, 2016: Atlantic-induced pantropical climate change over the past three decades. Nat. Climate Change, 6, 275-279, https://doi.org/10.1038/nclimate2840.
__, Z.-Z. Hu, and E. Becker, 2019a: On the westward shift of tropical Pacific climate variability since 2000. Climate Dyn., 53, 2905-2918, https://doi.org/10.1007/s00382-019. 04666-8.

- - - , and B. Huang, 2019b: Contributions of atmosphereocean interaction and low-frequency variation to intensity of strong El Niño events since 1979. J. Climate, 32, 1381-1394, https://doi.org/10.1175/JCLI-D-18-0209.1.

,,-- P. Liang, and J. Zhu, 2019c: Contrastive influence of ENSO and PNA on variability and predictability of North American winter precipitation. J. Climate, 32, 6271-6284, https://doi.org/10.1175/JCLI-D-19-0033.1.

Li, Y., J. P. Li, W. J. Zhang, Q. L. Chen, J. Feng, F. Zheng, W. Wang, and X. Zhou, 2017: Impacts of the tropical Pacific cold tongue mode on ENSO diversity under global warming. J. Geophys. Res. Oceans, 122, 8524-8542, https://doi.org/ 10.1002/2017JC013052.

Liebmann, B., and C. A. Smith, 1996: Description of a complete (interpolated) outgoing longwave radiation dataset. Bull. Amer. Meteor. Soc., 77, 1275-1277.

Lloyd, J., E. Guilyardi, H. Weller, and J. Slingo, 2009: The role of atmosphere feedbacks during ENSO in the CMIP3 models. Atmos. Sci. Lett., 10, 170-176, https://doi.org/10.1002/ asl.227.

Lübbecke, J. F., and M. J. McPhaden, 2014: Assessing the twentyfirst-century shift in ENSO variability in terms of the Bjerknes stability index. J. Climate, 27, 2577-2587, https://doi.org/ 10.1175/JCLI-D-13-00438.1.

Luo, J.-J., W. Sasaki, and Y. Masumoto, 2012: Indian Ocean warming modulates Pacific climate change. Proc. Natl. Acad. Sci. USA, 109, 18 701-18 706, https://doi.org/10.1073/pnas.1210239109.

McPhaden, M. J., 2012: A 21st century shift in the relationship between ENSO SST and warm water volume anomalies. Geophys. Res. Lett., 39, L09706, https://doi.org/10.1029/2012GL051826.

_- 2015: Playing hide and seek with El Niño. Nat. Climate Change, 5, 791-795, https://doi.org/10.1038/nclimate2775.

- and D. Zhang, 2004: Pacific Ocean circulation rebounds. Geophys. Res. Lett., 31, L18301, https://doi.org/10.1029/2004GL020727.

—_, and X. Zhang, 2009: Asymmetry in zonal phase propagation of ENSO sea surface temperature anomalies. Geophys. Res. Lett., 36, L13703, https://doi.org/10.1029/2009GL038774.

_ , and Coauthors, 1998: The Tropical Ocean-Global Atmosphere (TOGA) observing system: A decade of progress. J. Geophys. Res., 103, 14 169-14240, https://doi.org/10.1029/97JC02906.

_ , S. E. Zebiak, and M. H. Glantz, 2006: ENSO as an integrating concept in Earth science. Science, 314, 1740-1745, https:/ doi.org/10.1126/science.1132588.

— to changing background conditions in the tropical Pacific Ocean. Geophys. Res. Lett., 38, L15709, https://doi.org/ 10.1029/2011GL048275.

Meehl, G. A., and W. M. Washington, 1996: El Niño-like climate change in a model with increased atmospheric $\mathrm{CO}_{2}$ concentrations. Nature, 382, 56-60, https://doi.org/10.1038/382056a0.

Meinen, C. S., and M. J. McPhaden, 2000: Observations of warm water volume changes in the equatorial Pacific and their relationship to El Niño and La Niña. J. Climate, 13, 3551-3559, https://doi.org/ 10.1175/1520-0442(2000)013<3551:OOWWVC>2.0.CO;2.

Meyers, S. D., B. G. Kelly, and J. J. O'Brien, 1993: An introduction to wavelet analysis in oceanography and meteorology: With application to the dispersion of Yanai waves. Mon. Wea. Rev., 121, 2858-2866, https://doi.org/10.1175/1520-0493(1993) $121<2858$ :AITWAI $>2.0$.CO;2. 
National Research Council, 2010: Assessment of Intraseasonal to Interannual Climate Prediction and Predictability. National Academies Press, 192 pp.

Neske, S., and S. McGregor, 2018: Understanding the warm water volume precursor of ENSO events and its interdecadal variation. Geophys. Res. Lett., 45, 1577-1585, https://doi. org/10.1002/2017GL076439.

Newman, M., and P. Sardeshmukh, 2017: Are we near the predictability limit of tropical Indo-Pacific sea surface temperature? Geophys. Res. Lett., 44, 8520-8529, https://doi.org/ 10.1002/2017GL074088.

Nitta, T., and S. Yamada, 1989: Recent warming of tropical sea surface temperature and its relationship to the Northern Hemisphere circulation. J. Meteor. Soc. Japan, 67, 375-383, https://doi.org/10.2151/jmsj1965.67.3_375.

Ogata, T., S.-P. Xie, A. Wittenberg, and D.-Z. Sun, 2013: Interdecadal amplitude modulation of El Niño-Southern Oscillation and its impact on tropical Pacific decadal variability. J. Climate, 26, 7280-7297, https://doi.org/10.1175/JCLI-D-12-00415.1.

Okumura, Y., 2013: Origins of tropical Pacific decadal variability: Role of stochastic atmospheric forcing from the South Pacific. J. Climate, 26, 9791-9796, https://doi.org/10.1175/JCLI-D-1300448.1.

— and La Niña and the linkage to tropical Pacific decadal variability. J. Climate, 30, 4705-4733, https://doi.org/10.1175/ JCLI-D-16-0680.1.

Peng, P., A. Kumar, and Z.-Z. Hu, 2018: What drove the Pacific and North America climate anomalies in winter 2014/15? Climate Dyn., 51, 2667-2679, https://doi.org/10.1007/s00382-017-4035-9.

Planton, Y., J. Vialard, E. Guilyardi, M. Lengaigne, and T. Izumo, 2018: Western Pacific oceanic heat content: A better predictor of La Niña than of El Niño. Geophys. Res. Lett., 45, 9824-9833, https://doi.org/10.1029/2018GL079341.

Puy, M., and Coauthors, 2017: Influence of westerly wind events stochasticity on El Niño amplitude: The case of 2014 vs. 2015. Climate Dyn., 52, 7435-7454, https://doi.org/10.1007/s00382-017-3938-9.

Rasmusson, E. M., and T. H. Carpenter, 1982: Variations in tropical sea surface temperature and surface wind fields associated with the Southern Oscillation/El Niño. Mon. Wea. Rev., 110, 354-384, https://doi.org/10.1175/1520-0493(1982)110<0354: VITSST $>2.0 . \mathrm{CO} ; 2$

_ , and J. M. Wallace, 1983: Meteorological aspects of the El Niño/Southern Oscillation. Science, 222, 1195-1202, https:// doi.org/10.1126/science.222.4629.1195.

Rodgers, K. B., P. Friederichs, and M. Latif, 2004: Tropical Pacific decadal variability and its relation to decadal modulations of ENSO. J. Climate, 17, 3761-3774, https://doi.org/10.1175/15200442(2004)017<3761:TPDVAI >2.0.CO;2.

Saha, S., and Coauthors, 2010: The NCEP Climate Forecast System Reanalysis. Bull. Amer. Meteor. Soc., 91, 1015-1057, https:// doi.org/10.1175/2010BAMS3001.1.

— , and Coauthors, 2014: The NCEP Climate Forecast System version 2. J. Climate, 27, 2185-2208, https://doi.org/10.1175/ JCLI-D-12-00823.1.

Santoso, A., and Coauthors, 2015: ENSO extremes and diversity: Dynamics, teleconnections, and impacts. Bull. Amer. Meteor. Soc., 96, 1969-1972, https://doi.org/10.1175/BAMS-D-15-00141.1.

Sarachik, E. S., and M. A. Cane, 2010: The El Niño-Southern Oscillation Phenomenon. Cambridge University Press, 384 pp.

Schneider, E. K., L. Bengtsson, and Z.-Z. Hu, 2003: Forcing of Northern Hemisphere climate trends. J. Atmos. Sci., 60, 1504-1521, https:// doi.org/10.1175/1520-0469(2003)060<1504:FONHCT > 2.0.CO;2
Schopf, P. S., and R. J. Burgman, 2006: A simple mechanism for ENSO residuals and asymmetry. J. Climate, 19, 3167-3179, https://doi.org/10.1175/JCLI3765.1.

Seo, K.-H., and Y. Xue, 2005: MJO-related oceanic Kelvin waves and the ENSO cycle: A study with the NCEP Global Ocean Data Assimilation System. Geophys. Res. Lett., 32, L07712, https://doi.org/10.1029/2005GL022511.

Sun, F., and J.-Y. Yu, 2009: A 10-15-yr modulation cycle of ENSO intensity. J. Climate, 22, 1718-1735, https://doi.org/10.1175/ 2008JCLI2285.1.

Sun, T., and Y. M. Okumura, 2019: Role of stochastic atmospheric forcing from the South and North Pacific in tropical Pacific decadal variability. J. Climate, 32, 4013-4038, https://doi.org/ 10.1175/JCLI-D-18-0536.1.

Thual, S., B. Dewitte, N. Ayoub, and O. Thual, 2013: An asymptotic expansion for the recharge-discharge model of ENSO. J. Phys. Oceanogr., 43, 1407-1416, https://doi.org/10.1175/JPO-D-12-0161.1.

Timmermann, A., J. Oberhuber, A. Bacher, M. Esch, M. Latif, and E. Roeckner, 1999: Increased El Niño frequency in a climate model forced by future greenhouse warming. Nature, 398, 694-697, https://doi.org/10.1038/19505.

— , and Coauthors, 2018: El Niño-Southern Oscillation complexity. Nature, 559, 535-545, https://doi.org/10.1038/s41586-018-0252-6.

Ting, M., and P. D. Sardeshmukh, 1993: Factors determining the extratropical response to equatorial diabatic heating anomalies. J. Atmos. Sci., 50, 907-918, https://doi.org/10.1175/15200469(1993)050<0907:FDTERT > 2.0.CO;2.

Tippett, M. K., A. G. Barnston, and S. Li, 2012: Performance of recent multimodel ENSO forecasts. J. Appl. Meteor. Climatol., 51, 637654, https://doi.org/10.1175/JAMC-D-11-093.1.

Trenberth, K. E., and D. P. Stepaniak, 2001: Indices of El Niño evolution. J. Climate, 14, 1697-1701, https://doi.org/10.1175/ 1520-0442(2001)014<1697:LIOENO>2.0.CO;2.

Vimont, D. J., 2005: The contribution of the interannual ENSO cycle to the spatial pattern of decadal ENSO-like variability. J. Climate, 18, 2080-2092, https://doi.org/10.1175/JCLI3365.1.

Wallace, J. M., and D. S. Gutzler, 1981: Teleconnections in the geopotential height field during the Northern Hemisphere winter. Mon. Wea. Rev., 109, 784-812, https://doi.org/10.1175/ 1520-0493(1981)109<0784:titghf > 2.0.co;2.

Wang, B., 1995: Interdecadal changes in El Niño onset in the last four decades. J. Climate, 8, 267-285, https://doi.org/10.1175/ 1520-0442(1995)008<0267:ICIENO > 2.0.CO;2.

— , and S.-I. An, 2002: A mechanism for decadal changes of ENSO behavior: Roles of background wind changes. Climate Dyn., 18, 475-486, https://doi.org/10.1007/s00382-001-0189-5.

Wang, C., and J. Picaut, 2004: Understanding ENSO physics-A review. Earth's Climate: The Ocean-Atmosphere Interaction, Geophys. Monogr., Vol. 147, Amer. Geophys. Union, 21-48, https://doi.org/10.1029/147GM02.

Wang, L., J.-Y. Yu, and H. Paek, 2017: Enhanced biennial variability in the Pacific due to Atlantic capacitor effect. Nat. Commun., 8, 14887, https://doi.org/10.1038/ncomms14887.

Wang, W., M. Chen, and A. Kumar, 2010: An assessment of the CFS real-time seasonal forecasts. Wea. Forecasting, 25, 950969, https://doi.org/10.1175/2010WAF2222345.1.

Wen, C., A. Kumar, X. Xue, and M. J. McPhaden, 2014: Changes in tropical Pacific thermocline depth and their relationship to ENSO after 1999. J. Climate, 27, 7230-7249, https://doi.org/ 10.1175/JCLI-D-13-00518.1.

Wittenberg, A. T., 2009: Are historical records sufficient to constrain ENSO simulations? Geophys. Res. Lett., 36, L12702, https://doi.org/10.1029/2009GL038710. 
Xiang, B., B. Wang, and T. Li, 2013: A new paradigm for the predominance of standing central Pacific warming after the late 1990s. Climate Dyn., 41, 327-340, https://doi.org/10.1007/ s00382-012-1427-8.

Xie, F., and Coauthors, 2016: A connection from Arctic stratospheric ozone to El Niño-Southern Oscillation. Environ. Res. Lett., 11, 124026, https://doi.org/10.1088/1748-9326/11/12/124026.

Xie, P., and P. A. Arkin, 1997: Global precipitation: A 17-year monthly analysis based on gauge observations, satellite estimates, and numerical model outputs. Bull. Amer. Meteor. Soc., 78, 2539-2558, https://doi.org/10.1175/1520-0477(1997) $078<2539$ :GPAYMA $>2.0$. CO 2 .

Xie, R., and F.-F. Jin, 2018: Two leading ENSO modes and El Niño types in the Zebiak-Cane model. J. Climate, 31, 1943-1962, https://doi.org/10.1175/JCLI-D-17-0469.1.

Xu, K., W. Wang, B. Liu, and C. Zhu, 2019: Weakening of the El Niño amplitude since the late 1990s and its link to decadal change in the North Pacific climate. Int. J. Climatol., 39, 41254138, https://doi.org/10.1002/joc.6063.

Yeh, S., J. Kug, B. Dewitte, M. Kwon, B. P. Kirtman, and F.-F. Jin, 2009: El Niño in a changing climate. Nature, 461, 511-514, https://doi.org/10.1038/nature08316.

_- and Coauthors, 2018: ENSO atmospheric teleconnections and their response to greenhouse gas forcing. Rev. Geophys., 56, 185-206, https://doi.org/10.1002/ 2017RG000568.

Yu, J.-Y., and S.-W. Fang, 2018: The distinct contributions of the seasonal footprinting and charged-discharged mechanisms to ENSO complexity. Geophys. Res. Lett., 45, 6611-6618, https:// doi.org/10.1029/2018GL077664.

— P.-K. Kao, H. Paek, H.-H. Hsu, C.-W. Hung, M.-M. Lu, and S.-I. An, 2015: Linking emergence of the central-Pacific El
Niño to the Atlantic multidecadal oscillation. J. Climate, 28, 651-662, https://doi.org/10.1175/JCLI-D-14-00347.1.

Zhang, H., A. Clement, and P. N. Di Nezio, 2014: The South Pacific meridional mode: A mechanism for ENSO-like variability. J. Climate, 27, 769-783, https://doi.org/10.1175/JCLI-D-1300082.1.

Zhang, R.-H., F. Zheng, J. Zhu, and Z. Wang, 2013: A successful real-time forecast of the 2010-11 La Niña event. Sci. Rep., 3, 1108, https://doi.org/10.1038/srep01108.

Zhang, T., M. P. Hoerling, J. Perlwitz, and T. Xu, 2016: Forced atmospheric teleconnections during 1979-2014. J. Climate, 29, 2333-2357, https://doi.org/10.1175/JCLI-D-15-0226.1.

Zhang, W. J., J. P. Li, and X. Zhao, 2010: Sea surface temperature cooling mode in the Pacific cold tongue. J. Geophys. Res., 115 C12042, https://doi.org/10.1029/2010JC006501.

Zhang, Y., J. M. Wallace, and D. S. Battisti, 1997: ENSO-like interdecadal variability: 1900-93. J. Climate, 10, 1004-1020, https:// doi.org/10.1175/1520-0442(1997)010<1004:ELIV>2.0.CO;2.

Zhao, M., H. H. Hendon, O. Alves, G. Liu, and G. Wang, 2016: Weakened eastern Pacific El Niño predictability in the early twenty-first century. J. Climate, 29, 6805-6822, https://doi.org/ 10.1175/JCLI-D-15-0876.1.

Zheng, F., and J.-Y. Yu, 2017: Contrasting the skills and biases of deterministic predictions for the two types of El Niño. Adv. Atmos. Sci., 34, 1395-1403, https://doi.org/10.1007/s00376-017-6324-y.

Zheng, Z., Z.-Z. Hu, and M. L'Heureux, 2016: Predictable components of ENSO evolution in real-time multi-model predictions. Sci. Rep., 6, 35909, https://doi.org/10.1038/srep35909.

Zhu, J., A. Kumar, B. Huang, M. A. Balmaseda, Z.-Z. Hu, L. Marx, and J. L. Kinter III, 2016: The role of off-equatorial surface temperature anomalies in the $2014 \mathrm{El}$ Niño prediction. Sci. Rep., 6, 19677, https://doi.org/10.1038/srep19677. 